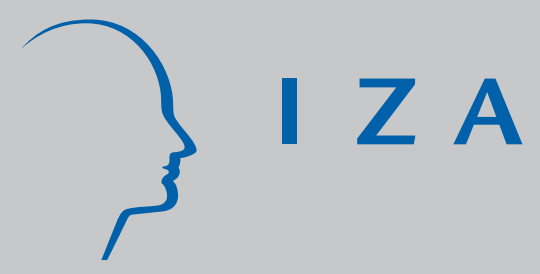

IZADP No. 3659

Urban-Rural Consumption Inequality in China from 1988 to 2002: Evidence from Quantile Regression Decomposition

Zhaopeng Qu

Zhong Zhao

August 2008 


\title{
Urban-Rural Consumption Inequality in China from 1988 to 2002: Evidence from Quantile Regression Decomposition
}

\author{
Zhaopeng Qu \\ Beijing Normal University \\ and IZA \\ Zhong Zhao \\ IZA
}

Discussion Paper No. 3659

August 2008

IZA

P.O. Box 7240

53072 Bonn

Germany

Phone: +49-228-3894-0

Fax: +49-228-3894-180

E-mail: iza@iza.org

Any opinions expressed here are those of the author(s) and not those of IZA. Research published in this series may include views on policy, but the institute itself takes no institutional policy positions.

The Institute for the Study of Labor (IZA) in Bonn is a local and virtual international research center and a place of communication between science, politics and business. IZA is an independent nonprofit organization supported by Deutsche Post World Net. The center is associated with the University of Bonn and offers a stimulating research environment through its international network, workshops and conferences, data service, project support, research visits and doctoral program. IZA engages in (i) original and internationally competitive research in all fields of labor economics, (ii) development of policy concepts, and (iii) dissemination of research results and concepts to the interested public.

IZA Discussion Papers often represent preliminary work and are circulated to encourage discussion. Citation of such a paper should account for its provisional character. A revised version may be available directly from the author. 


\section{ABSTRACT \\ Urban-Rural Consumption Inequality in China from 1988 to 2002: Evidence from Quantile Regression Decomposition}

One of the most notable social phenomena in China is the large urban-rural disparity. There are many studies of it, but most of them focus on income or earnings inequality. In this paper, we investigate the consumption disparity between urban and rural households in China from 1988 to 2002. Our results suggest that low quantiles are associated with large consumption disparity. The price effect is the dominant factor for the urban-rural consumption disparity. This disparity increased significantly, both at mean and at every quantile, from 1988 to 2002. However, most of the increase happened from 1988 to 1995, and this increase was mainly from the higher growth rate of urban household consumption. Our results also suggest that rural-urban migration and improvement of the rural educational level are very helpful in reducing urban-rural disparity.

JEL Classification: O18, O53, C15

Keywords: inequality, consumption, quantile regression decomposition, China

Corresponding author:

Zhong Zhao

IZA

P.O. Box 7240

D-53072 Bonn

Germany

E-mail: zhao@iza.org

\footnotetext{
"We would like to thank the participants in the IZA seminar; the 2008 Summer School on Development Economics jointly organized by the University of Verona, BREAD, and CEPR; and the $83^{\text {rd }}$ Annual Conference of the Western Economic Association International for their helpful comments, and are grateful to Klara Sabirianova and Yuriy Gorodnichenko for sharing with us their Stata code for the Machado-Mata decomposition algorithm. Zhaopeng Qu would like to acknowledge financial support and hospitality from the IZA Scholarship program. The usual disclaimers apply.
} 


\section{Introduction}

The widening income and earnings disparities between urban and rural China are one of the most remarkable social phenomena in recent years. As shown in Figure 1, in 1978 the urban-to-rural income ratio was 2.5. From the end of the 1970s, China began to reform its economic system, starting from the rural areas, where it abandoned the commune system and returned economic freedom to its farmers through the household responsibility system. This reform greatly enhanced incentives and increased productivity in rural China, as shown in Lin (1992). Consequently, the urban-rural income ratio fell considerably, from 2.5 in 1978 to 1.82 in 1983. However, China then expanded its reform into urban areas, while in the rural areas, after the introduction of the household responsibility system, the reform was stagnant. The urban-rural income ratio has risen again, and in 2006 it reached alarming level of 3.3.

-------Figure 1 about here---------

The significant disparity between urban and rural China is well recognized in the academies. Various aspects of this disparity have attracted much attention from economists. For examples, among many other studies, papers in the collected volumes of Zhao, Griffin, Li, and Zhu (1994), Zhao, Li, and Riskin (1999), and Li, Sicular, and Gustafsson (2008) were devoted to income inequality. Knight and Li (1996) investigated the differential educational attainment in urban and rural China, and found there was considerable inequality of educational opportunity. Knight and Song (1999) carefully examined many dimensions of the urban-rural China disparities, including income, 
education, health, and housing. Tsui (1993) and Kanbur and Zhang (1999) found urbanrural inequality was an important contributor to the overall Chinese regional inequality.

The Chinese government has also recognized the urban-rural disparity for a long time. In fact, a large portion of this disparity has resulted from the urban-biased development strategy of Chinese government since 1950s. However, unlike previous governments, the current government is trying to narrow this disparity. In 2005, for that purpose, the Chinese central government eliminated agricultural taxation and launched an ambitious project, the New Village Movement, which is somewhat similar to the South Korean New Village Movement in the 1970s, with the aim of modernizing China's countryside.

However, there is little or no study of consumption inequality between urban and rural households in China. Arguably, consumption is a better measure of long-term family well-being in that it reflects the life-cycle earning capacity of a household, whereas income and earnings can easily be affected by temporary shocks (see Cutler and Katz 1992), especially in rural China, and permanent income and earnings are hard to

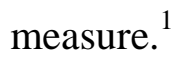

In this paper, we use three waves of consumption data from the China Household Income Project in 1988, 1995, and 2002 to investigate the consumption disparity between urban and rural households in China. This study will provide insight into Chinese urbanrural disparity beyond the other dimensions examined in the previous literature. That is the first contribution of this paper.

\footnotetext{
${ }^{1}$ Meng (2003) found evidence supporting consumption smoothing and precautionary saving in urban China.
} 
The second contribution of this paper is that besides looking into the average disparity between urban and rural China, we also apply the regression decomposition technique recently developed by Machoda and Mata (2005) to investigate the distributional difference between urban and rural consumption. ${ }^{2}$ In addition, we examine the dynamics and changes of the urban-rural consumption disparity from 1988 to 2002.

As the final contribution of the paper, we examine the impact of urban-rural migration on urban-rural disparity in 2002. This analysis sheds light on the role of ruralurban migration on economic development and poverty reduction in rural China.

Our results suggest that low quantiles are associated with large consumption disparity. This disparity had increased significantly, both at mean and at every quantile, from 1988 to 2002. However, most of the increase happened from 1988 to 1995, and this increase was mainly due to the higher growth rate of urban household consumption. Our decomposition exercise shows that the price effect is the dominant factor for the urbanrural consumption disparity, though the importance of endowment is increasing over time. Our analysis also suggests that rural-urban migration and improvement of the rural educational level are very helpful in reducing urban-rural disparity.

The rest of the paper is organized as follows: Section 2 provides some historical details on urban-rural segregation in China and on Chinese economic reform since 1978. Section 3 describes the data set and the construction of the variables; it also provides descriptive statistics. Section 4 takes the first look at the urban-rural consumption inequality using the Blinder-Oaxaca decomposition. Section 5 outlines the quantile

\footnotetext{
${ }^{2}$ Nguyen, Albrecht, Vroman, and Westbrook (2007) apply this approach to study urban-rural inequality in Vietnam. Other applications include Albrecht, Bjorklund, and Vroman (2003) on the gender wage differential in Sweden, and Autor, Katz, and Kearney (2005) on US wage inequality, among others.
} 
decomposition technique, and presents related findings. Section 6 carries out several robustness checks and extensions, and Section 7 gives concluding remarks.

\section{Urban-Rural Segregation and Chinese Economic Reform}

To put our analysis into historical perspective, and to facilitate to interpret our results, in this section we briefly describe the urban-rural segregation in China, and outline the timeline of China economic reform since 1978.

\section{Urban-Rural Segregation ${ }^{3}$}

Urban-rural segregation in China has been legally enforced by the household registration (hukou) system since the 1950s, and this segregation was intensified in the 1960s following the failure of the Great Leap Forward and the devastating famine in the late 1950s. The more profound reason behind this segregation was the Chinese government's urban- and heavy-industry-biased development strategy beginning in the 1950s. The farmers were considered by the government as an important resource to facilitate this distorted macro policy, and it was necessary to tie them to the land to provide cheap agricultural products to the industrial sector and urban areas (see Lin, Cai, and $\mathrm{Li}, 1994)$.

In practice, the earnings of farmers crucially depended on their daily participation in collective farming: each farmer became a member of a collective production team. The opportunity cost of leaving the countryside was prohibitively high. Through the hukou system, the government allocated housing and jobs, and rationed food and other

\footnotetext{
${ }^{3}$ This part of discussion is mainly based on Zhao (2005).
} 
necessities. These arrangements made it almost impossible for people without urban hukou to live in an urban area; see Zhao (1999).

As consequences of the segregation, the average migration rate for China was only 0.24, compared with world average of 1.84 from 1950 to 1990; see Zhao (2000). The urbanization process was severely hindered. The urbanization level was $11.7 \%$ in 1949; by 1978 it had increased by less than 3 percentage points, to around $14.5 \%$ (see Wu 1994). The urban-rural disparity was much more pronounced than in most countries, and the urban-rural income ratio was more than 3.

The commune system in rural China does not exist any more, but the basics of the hukou system remained intact until very recently, and the hukou system is still the major factor behind urban-rural disparity, as shown in Liu (2005).

\section{Economic Reform}

Figure A1 in the appendix outlines the timeline of China economic reform since 1978. China started its economic reform in rural areas, in 1978. The household responsibility system emerged and eventually replaced the commune system. This reform restored the central role of family in productive activity in rural China, and returned economic freedom to the farmer. The household responsibility system totally changed the incentive structure and greatly improved productivity. Lin (1992) estimated that nearly half of the total agricultural output growth during 1978-1984 resulted from this reform. This is by far the most important reform in rural areas since 1978 .

In contrast with the rural areas, in the urban areas the reform was carried out piece by piece. As an exploratory project, the government first created special economic zones in four coastal cities in 1979. Besides preferential treatment, such as special tax laws, for 
the special economic zones, government also allowed the operation of firms in these zones in accordance with the principles of a market economy instead of a planned economy. The urban labor market did not changed significantly until the mid 1980s. From 1986, the state-owned enterprises (SOEs) were allowed a more flexible labor policy. The legalization of the private economy in 1988 further improved the flexibility of the urban labor market. But the big change in the urban labor market happened in the late 1990s. During this period, the SOEs massively laid off workers, life tenure was abolished, and unemployment became a daily social phenomenon. Jobs were no longer planned and allocated by the government; instead, the market took over the function of matching supply and demand for labor, and the market also set the price of labor, at least for the majority of the work force.

\section{Data and Descriptive Statistics}

The household consumption data are from the 1988, 1995, and 2002 waves of the China Household Income Project (CHIP). Based on the sampling frame used by the National Bureau of Statistics of China (NBS), each of the three surveys of CHIP covers both urban and rural areas in selected provinces in China, ${ }^{4}$ and follows the actual distribution of population across these provinces (see Demurger, Fournier, and $\mathrm{Li}$, 2006). ${ }^{5}$ It has collected detailed household and individual information, such as income

\footnotetext{
${ }^{4}$ Like most surveys in China, CHIP divides the urban and rural samples by legal status in the household registration system, and most of our analysis on urban-rural disparity is based on this division, which is the usual practice in the literature on that subject. The 2002 wave of CHIP, in additional to the urban and rural samples, has a rural-migrant sample, so we will also take migrants into consideration in 2002.

${ }^{5}$ In China, there are four types of provincial-level government, and a total of 34 provincial-level administrative regions. Among them, there are 23 provinces, 4 provincial-level municipalities, 5 autonomous regions, and 2 special administrative districts. We refer to all of them as provinces in this paper.
} 
and expenditure, demographic characteristics, and work and employment information. CHIP is well known as one of the most representative household-level data sets on China.

It is worth noting that CHIP does not cover all provinces in China, and not all three waves cover the same group of provinces. In order to control for possible composition effects due to different sampled provinces in different waves, we restricted our analysis to the provinces that are present in all three waves. ${ }^{6}$ Furthermore, we dropped the bottom $1 \%$ and top $1 \%$ of rural households and of urban households separately, in terms of household consumption, in order to avoid outliers. The final sample has 2,197 rural households and 7,930 urban households in 1988; 2,208 and 2,594 in 1995; 3,304 and 4,468 in 2002.

The main variable that we are investigating in this paper is consumption per capita during the survey year. To construct our main variable, first we calculate the consumption at the household level. The household consumption in our paper includes all food and nondurable goods consumed during the year, expenditures on education and health, self-consumed home-produced goods in rural households, and all nondurable inkind transfers received by the households. ${ }^{7}$ Then we divide household consumption by household size, and finally we adjust for price level and obtain the real consumption expenditure per capita measured in 1988 currency, using the consumer price index (CPI) from the National Bureau of Statistics of China. ${ }^{8,9}$

\footnotetext{
${ }^{6}$ These provinces are Beijing, Shanxi, Liaoning, Jiangsu, Anhui, Henan, Hubei, Guangdong, Yunnan, and Gansu. A map of these provinces is shown in Figure A2 in the appendix. Though CHIP does not cover the whole of China, the provinces in CHIP as well as the ones used in our paper are representative of different regions in China.

${ }^{7}$ Like almost all the household surveys, CHIP only has consumption information at the household level, not at the individual level.

${ }^{8}$ The CPIs are from table 14-8, table 8-5, and table 9-5 in NBS (1989b, 1996b, and 2003b), respectively.

${ }^{9}$ In section 5, we also use the provincial-level CPI proposed in Brandt and Holz (2006) as a robustness check.
} 
As a robustness check, we also experiment on including the flow of services from the stock of consumer durables and the rental value of self-owned housing as part of household consumption. We term this the augmented consumption in this paper.

Tables A.1 to A.3 in the appendix show the main variables used in this paper. In all three tables, we provide both unweighted and weighted descriptive statistics. For the weighted statistics, we reweight the samples by the actual population size of the provinces. So after weighting, the share of observations in each province in the sample is the same as the actual share of the population in each province. ${ }^{10}$

From these tables, we can see that for all three waves, urban households consume more per capita, have smaller household size, and are more likely to have a female household head. The urban household heads are older, more educated, and more likely to be Communist Party members.

Figure 2 shows kernel densities of consumption, food consumption, augmented consumption, and income in urban and rural areas separately for the three waves. There are three things worth noting. First, both income and consumption inequalities have increased dramatically from 1988 to 2002. Second, most of the increase of the inequalities happened during 1988 to 1995. Third, urban-rural consumption disparity (whether measured by consumption, food consumption, or augmented consumption) also increased significantly from 1988 to 2002. Again, most of the changes happened during 1988 to 1995.

\footnotetext{
${ }^{10}$ When we do the decomposition exercises, we further reweight the sample by the actual rural-urban population share in each province. The weights are from table 2, table 6-2, and table 4-5 in NBS (1989a, 1996a, and 2003a), respectively.
} 
Figure 3 presents urban-rural gaps in consumption, food consumption, augmented consumption, and income at quantiles. This figure confirms our observations in Figure 2 that urban-rural disparities increased from 1988 to 2002, but there are differences between consumption disparity and income disparity. For the consumption disparity, most of the increase happened from 1988 to 1995; however, most of the increase of income disparity happened from 1995 to 2002. The gaps in all three years are downward sloping. However, the slope of the gap in income is steeper than the slope of consumption, and the slope of food consumption in 2000 is almost zero, which means that the urbanrural income disparity is larger for low-income households, but consumption disparity is more evenly distributed across quantiles.

-------Figure 3 about here----------

Table 1 presents our first set of regression estimates for the urban-rural consumption inequality. In this table, we only control for province dummies, so the coefficients of the urban dummy in this table tell us the raw gap between urban and rural consumption after controlling for regional differences, which are very important in China.

--------Table 1 about here---------- 
In Table 1, several observations stand out. First, all the coefficients of the urban dummy (i.e., the estimated urban-rural gap) are economically significant and are statistically significant at the $1 \%$ level. Second, these coefficients are decreasing in quantiles, which is consistent with the findings in Figure 3. Third, the urban-rural gap is increasing with time. Fourth, the interprovince inequality is very significant. Almost all provinces (Guangdong is an exception) are worse off than Beijing, the capital of China, in terms of real consumption expenditure per capita. Last, the urban dummy plus province dummies can explain a large portion of consumption variation in China. This is especially true for 1995 and 2002, and the adjusted $R$-squared is around 0.6 for both years. ${ }^{11}$

Of course, the urban-rural inequality in Table 1 might be due to endowment differences, or to a difference in returns to the same endowment between urban and rural China, or both. The remainder of this paper will be devoted to disentangling these two effects.

\section{Blinder-Oaxaca Decomposition}

\section{Framework}

In order to have a better understanding of the urban-rural consumption disparity, as the starting point, we begin with the Blinder-Oaxaca decomposition (Oaxaca, 1973;

\footnotetext{
${ }^{11}$ The regional inequality has also widened since the start of the reform; before the reform and even during the early 1980s, the regional inequality was not significant; see Gustafsson and Li (2005), Wu and Perloff (2005), and Table 2 in Kanbur and Zhang (2005). This is the reason that some poor provinces (according to current standard) - e.g., Yunnan - had positive coefficients in 1988. That the adjusted $R$-squared increased from 0.29 in 1988 to 0.61 in 1995 provides additional evidence of the significance of the increasing regional inequality.
} 
Blinder, 1973), to decompose the average difference in log consumptions between urban (u) and rural ( $r$ ) China as

$$
\begin{aligned}
& E\left[\ln Y_{u}\right]-E\left[\ln Y_{r}\right]= \\
& \left(E\left[X_{u}\right]-E\left[X_{r}\right]\right)^{\prime} \beta_{r}+E\left[X_{r}\right]^{\prime}\left(\beta_{u}-\beta_{r}\right)+\left(E\left[X_{u}\right]-E\left[X_{r}\right]\right)^{\prime}\left(\beta_{u}-\beta_{r}\right)
\end{aligned}
$$

where $Y$ denotes household consumption, $X$ is a vector of household and household-head characteristics (household size, age, gender, education, etc.), and $\beta$ is a vector of returns

to these characteristics. ${ }^{12}$ As indicated in equation (1), the decomposition makes use of the sample mean values of all characteristics and of the OLS estimates for the returns to these characteristics. The first term on the right-hand side of this equation is the effect of differences in mean characteristics of the two samples for identical returns: if the rural population had the endowment of urban population, what would the difference in consumption look like? This is usually termed the endowment effect. The second term is typically interpreted as the part of the urban-rural average consumption difference that is associated with differences in returns to individual and household characteristics across the two samples, i.e., the coefficient or price effect. The third term takes account of the fact that the urban and the rural sample differ in both endowments and returns to endowments.

\section{Results}

Table 2 presents results from the decomposition. There are two notable findings. First, the increase of urban-rural consumption inequality (from 0.44 to 1.24) from 1988 to

\footnotetext{
${ }^{12}$ For a list of the covariates, see tables A1 to A3 in the appendix.
} 
2002 is larger than the increase of urban-rural income inequality (from 0.66 to 0.94$){ }^{13}$ This may reflect that the income of urban households is underestimated, or that in-kind benefits and/or in-kind transfers from government are still an important component of urban households’ consumption.

Table 2 about here-

Second, for both consumption and income, the price effect is always the dominating factor in explaining the urban-rural gap in the three waves, though the endowment effect is getting more important. The fraction explained by the endowment effect is $16.9 \%, 12.9 \%$, and $27.9 \%$ in 1988,1994 , and 2002 , respectively, for consumption; it is $4.8 \%, 15.9 \%$, and $40.2 \%$ for income. The interaction part turns from positive in 1988 to negative in 2002, for both consumption and income. This implies that some of the endowments and prices moved in different directions from 1988 to 2002.

\section{Machado-Mata Decomposition}

\section{Framework}

Since household and household-head characteristics and coefficients of these characteristics can vary significantly across quantiles for a heterogeneous population, it is important to look into distributional effects and to decompose the urban-rural differentials illustrated in Figure 3 into not only differences in means of endowment, but

\footnotetext{
${ }^{13}$ The food consumption differential increased even faster, from 0.108 in 1988 to 1.066 in 2002.
} 
also differences in distributions of endowment. It is also essential to allow coefficients to vary across quantiles in order to capture the heterogeneity in returns.

Several approaches have been proposed in the literature in the wage and income inequality literature, such as Juhn, Murphy, and Pierce (1993) and DiNardo, Fortin, and Lemieux (1996), to accommodate heterogeneity. In this paper, we follow the quantile decomposition methods proposed by Machado and Mata (2005).

Let $Q_{\theta}(\ln y \mid x)$ for $\theta \in(0,1)$ denote the $\theta$ th quantile of the distribution of the log consumption given the vector $x$ of covariates. So the quantile regression equation is

$$
Q_{\theta}(\ln y \mid x)=x^{\prime} \beta(\theta),
$$

and the unconditional quantile distribution is

$$
Q_{\theta}(\ln y)=X^{\prime} \beta(\theta) \text {. }
$$

As in the previous section, we use $r$ to denote rural households and $u$ to denote urban households. Then the urban-rural consumption difference at quantiles is

$$
Q_{\theta}\left(\ln y_{u}, \beta(\theta)_{u}\right)-Q_{\theta}\left(\ln y_{r}, \beta(\theta)_{r}\right)=X_{u}{ }^{\prime} \beta(\theta)_{u}-X_{r}{ }^{\prime} \beta(\theta)_{r} \text {. }
$$

We are interested in a decomposition exercise similar to the Blinder-Oaxaca decomposition that can isolate the endowment effect and price effect at quantiles. Namely, we want to know the quantile difference due to endowment, i.e.,

$$
Q_{\theta}\left(\ln y_{u}, \beta(\theta)_{r}\right)-Q_{\theta}\left(\ln y_{r}, \beta(\theta)_{r}\right)=X_{u}{ }^{\prime} \beta(\theta)_{r}-X_{r}{ }^{\prime} \beta(\theta)_{r} \text {, }
$$

and that due to coefficients, i.e.,

$$
Q_{\theta}\left(\ln y_{r}, \beta(\theta)_{u}\right)-Q_{\theta}\left(\ln y_{r}, \beta(\theta)_{r}\right)=X_{r}{ }^{\prime} \beta(\theta)_{u}-X_{r}{ }^{\prime} \beta(\theta)_{r} .
$$

Machado and Mata (2005) provide a handy framework to achieve our goal. The technical details of their approach can be found in the technical appendix. It is worth 
noting that, as in the Blinder-Oaxaca decomposition, the endowment effect as in equation (5) and price effect as in equation (6) together will not exhaust the urban-rural gap.

\section{Decomposition between Urban and Rural China}

Figure 4 summarizes the quantile decomposition results. Whereas Nguyen, Albrecht, Vroman, and Westbrook (2007) found higher quantiles associated with larger consumption gaps in Vietnam, our results suggest that the consumption disparity is decreasing with increasing quantile in China, i.e., lower quantiles are associated with larger disparities, and this is especially true in 1988. However, the forces behind the shape of the urban-rural gap are not the same. In 1988 and 2002, the downward slope is mainly determined by the price effect, but in 1995, it is dictated by the endowment effect.

-------Figure 4 about here---------

From 1988 to 1994, the urban-rural consumption disparity increased dramatically for the whole distribution, but the change from 1994 to 2002 is much less pronounced. At each quantile, the price effect dominated the endowment effect for all three waves.

\section{The Role of Education}

Among the endowments, education certainly is one of the most important. It is worthwhile devoting some space to the role of education in the urban-rural disparity. Urban and rural household heads differ substantially in educational level (Panel A of Figure A3 in the appendix). Though the education level has increased for both urban and rural household heads, most of the increase for the college-and-above group is from the urban areas. There are also important differences in the coefficient of education. As 
shown in Panel B of Figure A3, in 1988 the coefficient of education for rural households was bigger than the one for urban households, i.e., the urban-rural education coefficient difference was negative; but this difference has been gradually reversed. ${ }^{14}$

To isolate the effect of education from other covariates, we follow the suggestion in Machado and Mata (2005), and the findings are shown in Figure $5 .{ }^{15}$ The most striking finding is that if rural household heads had the education level of urban household heads, there would be almost no urban-rural disparity. The difference in the coefficient of education between urban and rural households only plays a minor role. Our findings once again confirm the importance of human capital, and reinforce the view that improving education is the key to economic development and poverty reduction.

Figure 5 about here-

\section{Impact of Rural-Urban Migration}

Like most surveys in China, CHIP divides the urban and rural samples by legal status (hukou), and our analysis of urban-rural disparity until now has been based on this division. Under the hukou system, even if a person is living in and working in an urban (rural) area, she/he is still classified as a rural (urban) observation if she/he legally has a rural (urban) hukou. Since 1988, rural-urban migration has become a significant social phenomenon in China (Zhao 2005); however, the 1988 and 1995 waves of CHIP do not

\footnotetext{
${ }^{14}$ It needs to be pointed out that, as shown in Panel B of Figure A3, the urban-rural differences in return to education are not significant at the 5\% level for most quantiles in 1995 and 2002.

${ }^{15}$ However, Firpo, Fortin, and Lemieux (2007) argue that the solution of Machado and Mata (2005) is not totally correct, since it also changes the distribution of other variables that are correlated with education, and currently there is still no satisfactory way to isolate the effect of a single variable in the quantile decomposition framework.
} 
cover the rural-urban migrants. Luckily, in the 2002 wave of CHIP, it collected a ruralmigrant sample. This allows us to investigate the impact of the migration on urban-rural consumption disparity. We adopt two methods to merge the rural-migrant sample with the main CHIP sample. One is to maintain the usual practice in the literature on Chinese rural-urban comparison, and divide the households into urban and rural groups according to the household head's legal status, i.e., hukou. For this approach, we merge the observations in the migrant sample with the rural sample of their source provinces. This approach allows us to examine the role of rural-urban migration in reducing the urbanrural disparity. The other is to classify the households by residence; e.g., if a household is residing in an urban area, we treat it as an urban household regardless of the legal status of the household head. We merge the observations in the migrant sample with the urban sample of their current residing province. ${ }^{16}$

Comparing Panel A of Figure 6 with Figure 4, we can see that after we include rural migrants in the rural sample, the urban-rural gap has decreased, especially for the top quantiles, though the decomposition results are quite similar with and without the migrant sample. This is consistent with the theory and anecdotal evidence that migrants are seeking better economic opportunity in the cities. Our finding is also consistent with findings in Du, Park, and Wang (2005) and Ravallion and Chen (2007); the former found that migration increased per capita income in the source communities, and the latter found that it reduced rural poverty.

\footnotetext{
${ }^{16}$ For the first approach, we reweight the sample by the percentage of villagers who migrated to the cities in the source villages; the weight data come from the village survey of the 2002 wave of CHIP. For the second approach, we reweight the sample by the percentage of migrants in the receiving cities; the weights come from official statistics, given in Table 4-6 in NBS (2003b).
} 
--------Figure 6 about here----------

Panel B gives the results for classifying the household by resident location. Two conspicuous findings are that the urban-rural gap has become much flatter now, and that the disparity at bottom quantiles has decreased a lot. One explanation is that the rural migrants earned considerably less than the native urban residents and were concentrated at bottom quantiles. Including the rural migrants in the urban sample inevitably lowered the consumption level of urban households, especially for the households at lower quantiles. ${ }^{17}$

\section{Comparison between Consumption and Income}

For the sake of comparison, we present decomposition results on income in Figure 4A in the appendix. We have several observations. First, the slope of the gap in income is steeper than the slope of consumption in all three waves. Second, endowment plays an increasingly important role in explaining the urban-rural gap. Third, the rural households at the top quantiles experienced a larger increase of income from 1988 to 1995, while the increase in consumption was more evenly distributed across quantiles.

\section{Dynamics from 1988 to 2002}

This section explores the consumption changes across time. Figure 7 presents consumption gaps from 1988 to 1995 and from 1995 to 2002 separately for urban areas and rural areas. First, we look at the urban areas (Panel A). From 1988 to 1994, consumption for urban households had increased significantly across all quantiles, and the higher the quantile, the more the consumption had increased. From our decomposition

\footnotetext{
${ }^{17}$ In a separate ongoing study, we are comparing multiple dimensions of native urban residents, migrants in the cities, and rural residents still in the villages.
} 
exercise, it is clear that most of this increase came from the price effect. This is consistent with the fact that China was transiting from a planned economy to a market economy during this period, so the return to endowment would move closer to the market prices with time.

From 1995 to 2002, the consumption in urban areas kept increasing, but only marginally. A series of reforms in urban China [e.g., the reform of state-owned enterprises since 1993, elimination of the life-long tenure system, and the massive layoff of urban workers since 1997 (see Figure A1 in the appendix)] is likely the explanation behind the sluggish consumption growth rate of the urban households from 1995 to 2002 . These reforms not only had an impact on the level of earnings (and hence on consumption), but also increased the earnings volatility of urban workers; this in turn would decrease consumption. Nonetheless, from the decomposition analysis it is clear that the increases in both periods were driven by the price effect.

Figure 7 about here

Panel B in Figure 7 is a similar decomposition exercise for rural households. We can see that in rural areas the consumption had also increased from 1988 to 1995, though the amount of increase is much less than in urban areas. This increase can also explained mainly by the price effect. This is not surprising, since endowments, such as human capital, had not changed a lot from 1988 to 1995; instead, most of the increase in productivity came from improved incentives (viz., the transition from a commune system to a household responsibility system) as well as from the fact that the prices of 
agricultural products were moving closer to market prices. Price effects would inevitably reflect these changes.

Consumption kept increasing from 1995 to 2002, but at a slower rate. During this period, both price effect and endowment effect were important. The stagnation of prices of agricultural products and lack of institutional innovations and reforms in rural areas are likely behind the slow growth.

Comparing Panels A and B suggests that the increase of urban-rural disparity from 1988 to 1995 is mainly from the faster growth rate of consumption in urban areas. The consumption in rural areas was also growing, but the growth rate was much slower. From 1995 to 2002, the consumption growth in both rural and urban areas was sluggish.

\section{Robustness Check and Extensions}

In this section, we perform several robustness checks and extensions. First, we adjust per capita consumption by the OECD equivalence scale in order to accommodate possible effects of economies of scale and family structure on consumption. Second, we use the provincial CPI proposed by Brandt and Holz (2006) instead of the official CPI. Third, since there are no separate CPIs for urban and rural areas in Beijing, we exclude observations in Beijing from our analysis. Fourth, we include durables and housing in our consumption measurement, and finally, because China is still a developing country, we take a close look at food expenditure.

\section{Adjustment for Equivalence Scale}

In the previous section, we did not consider possible effects on household consumption of economies of scale with respect to household size and household age 
structure. Now we quantify the importance of these effects, applying the widely used OECD equivalence scale. ${ }^{18}$

Figure 8 presents urban-rural as well as across-time decomposition results using the modified OECD equivalence scale. Comparing Figure 8 with Figures 4 and 7, we find that applying the equivalence scale usually enhances the price effect. Nonetheless, the general pictures are quite similar with or without adjusting for the equivalence scale. ${ }^{19}$

-------Figure 8 about here---------

\section{Using the Provincial CPI of Brandt and Holz (2006)}

The main difference between the official CPI and the CPI of Brandt and Holz (2006) is that the official CPI does not allow for interprovince price differentials. Again, the main picture remains unchanged when we use the provincial CPI proposed by Brandt and Holz (2006) instead of the official CPI, though there are still several observations worth noting. Similarly to the study of income inequality by Demurger, Fournier, and Li (2006), using the CPI of Brandt and Holz reduces the urban-rural disparity in all three waves; see Figure 9. This CPI also makes the endowment effect more important, though the price effect is still the dominating one except in 1988. This CPI also affects the consumption change from 1995 to 2002, both in rural and in urban areas. After applying

\footnotetext{
${ }^{18}$ The old OECD equivalence scale assigns a weight of 1 to the first household member, of 0.7 to each additional adult, and of 0.5 to each additional child. The modified OECD equivalence scale assigns a weight of 1 to the first household member, of 0.5 to each additional adult, and of 0.3 to each child. Deaton (1997) provides a general discussion of equivalence scales.

${ }^{19}$ We also apply the old OECD equivalence scale. Figure A5 in the appendix summarizes the results, and it is very close to Figure 8 .
} 
this CPI, the positive though small change in urban areas became almost zero, and that in rural areas turned negative. ${ }^{20}$

-Figure 9 about here-

\section{Exclusion of Beijing Municipality Sample}

As another check on our analysis, we exclude Beijing from it, since there is only one single official CPI and also only one single CPI from Brandt and Holz (2006) for both urban and rural Beijing, which means we cannot adjust for the urban-rural price difference within Beijing. As shown in Figure A6 in the appendix, excluding Beijing has little impact on our previous findings.

\section{Augmented Consumption}

Here we include the flow of services from the stock of consumer durables and the imputed rental value of self-owned housing as part of household consumption. To estimate the values of the services from durables and the rental value of housing, we follow the assumptions used in Benjamin, Brandt, and Giles (2005) and Brauw and Giles (2008), viz., housing is consumed over a twenty-year period, and durable goods have a useful life of seven years. ${ }^{21}$

\footnotetext{
${ }^{20}$ This result is apparently due to different ways of constructing the CPI; however, it is hard to isolate which factor(s) contribute to it.

${ }^{21}$ We should admit that calculating the service value from durables and the rental value of self-owned housing is difficult. We need some assumptions for the calculation, and there are other assumptions than the ones we are using here. One reason for our choice is that we want our results to be comparable to previous literature on inequality and consumption in China.
} 
Figure 10 shows the decomposition exercises. For the urban-rural consumption disparity, if we replace the consumption by augmented consumption, the general picture remains unchanged, though the augmented consumption has slightly enhanced the urbanrural disparity (Panel A). However, when we look across time, we can see that both urban and rural households at top quantiles have a larger increase over time on using augmented consumption instead of consumption. This means rich households also have more durables and more real estate.

\section{Food Expenditure}

As the final piece of our analysis, we examine food expenditure, since China is still a developing economy, and poverty in rural areas as well as some urban areas is still substantial. For the poor families, food is definitely the most important and most expensive component in their consumption.

Our first observation is that for food expenditure, endowment effect dominated price effect for most of the distribution in 1988. In 1995 and 2002, the price effect was still the dominating one.

Second, from 1988 to 2002, food expenditure for rural households as well as for urban households had increased a lot. However, from 1995 to 2002, for most of the quantiles, there was almost no growth in food expenditure for urban households, and rural households experienced a negative growth of food consumption. ${ }^{22}$

\footnotetext{
${ }^{22}$ For the lack of growth of food expenditure for urban households from 1995 to 2002, one possible explanation is that in 1995, the urban households already had enough food, so there was no need to buy more even if the income was increased. However, it is hard to explain the negative growth of food expenditure in rural areas from 1995 to 2002. We examine the weight of the food consumed by the households in 1995 and 2002, and also find the negative trend. In 1995, the per capita food consumptions are 101, 125 and 36 kilograms for wheat, rice and other, and they are 84, 113 and 35 kilograms in 2002. These numbers are calculated from questions 901 and 803a in 1995 and 2002 questionnaires, respectively.
} 
Finally, we investigated the effect of rural-urban migration on food expenditure in 2002. The results are similar to the previous ones. Migration has reduced urban-rural disparity, and has made the slope of the gap flatter.

--Figure 11 about here---------

We also carried out several robust checks for food expenditure, such as adjustment for equivalence of scale, using the CPI of Brandt and Holz (2006), and excluding the Beijing sample (see appendix, Figure 7A). They have similar effects on food expenditure to those on our main consumption variable, and do not change our main findings.

\section{Conclusions}

In this paper, we use three waves of consumption data from the China Household Income Project to investigate the consumption disparity between urban and rural households in China from 1988 to 2002.

Our results suggest that low quantiles are associated with large consumption disparity. This finding is different from another study's finding in Vietnam. It shows a dismaying picture of rural low-income households and rural poverty.

After decomposing the disparity into price effect and endowment effect, we find that the price effect is the dominating factor. Further we find that if rural household heads had the same education as urban ones, a large portion of the urban-rural disparity would 
disappear. Our results also suggest that rural-urban migration and improving the rural educational level are very helpful in reducing urban-rural disparity.

From 1988 to 2002, the urban-rural consumption disparity increased significantly, both at mean and at every quantile. Most of the increase happened from 1988 to 1995. From 1995 to 2002, urban-rural disparity kept getting bigger, but at a much slower rate. Our across-time decomposition analysis further shows that the increase of urban-rural disparity from 1988 to 1995 is mainly from the higher growth rate of consumption in the urban areas. 


\section{References}

Albrecht, J., A. Bjorklund, and S. C. Vroman. (2003), "Is there a glass ceiling in Sweden?” Journal of Labor Economics, 21, 145-77.

Autor, D, L. Katz, and M. Kearney (2005), "Rising wage inequality: the role of composition and prices,” Working paper no. 11628, National Bureau of Economic Research, Cambridge, Massachusetts.

Benjamin, D., L. Brandt and J. Giles (2005), "The evolution of income inequality in rural China,” Economic Development and Cultural Change, 53, 769-824.

Blinder, A. S. (1973): “Wage discrimination: Reduced form and structural variables,” Journal of Human Resources, 8, 436-455.

Brandt, L. and C. A. Holz (2006), "Spatial price differences in China: estimates and implications,” Economic Development and Cultural Change, 55, 43-86.

Cutler, D. and L. Katz (1992), "Rising Inequality? Changes in the Distribution of Income and Consumption in the 1980’s,” The American Economic Review 82, 546-551.

Deaton, A. (1997), The Analysis of Household Surveys, The Johns Hopkins University Press, Baltimore.

Demurger, S., M. Fournier, and S. Li (2006), “Urban income inequality in China revisited (1988-2002),” Economic Letters 93, 354-359.

DiNardo, J., N. Fortin, and T. Lemieux (1996), "Labor market institutions and the distribution of wages, 1973-1992: A semi-parametric approach,” Econometrica 64, 1001-1044.

Du, Y., A. Park, and S. Wang (2005), “Migration and Rural Poverty in China,” Journal of Comparative Economics 33(4), 688-709.

Firpo, S., N. Fortin, and T. Lemieux (2007), "Decomposing wage distributions using recentered influence function regressions,” working paper. 
Gustafsson, B. and S. Li (2002), "Income inequality within and across counties in rural China 1988 and 1995,” Journal of Development Economics 69, 179-204.

Juhn, C., K. Murphy and B. Pierce (1993), "Wage inequality and the rise in returns to skill,” Journal of Political Economy, 101, 410-442.

Kanbur, R. and X. Zhang (1999), "Which regional inequality? The evolution of ruralurban and inland-coastal inequality in China from 1983 to 1995,” Journal of Comparative Economics, 27, 686-701.

Knight, J. and S. Li (1996), "Educational attainment and the rural-urban divide in China,” Oxford Bulletin of Economics and Statistics, 58, 83-117.

Knight, J. and L. Song (1999), The rural-urban divide: economic disparities and interactions in China, Oxford University Press, Oxford and New York.

Koenker, R. and G. Bassett (1978), “Regression quantiles,” Econometrica, 46, 33-50

Li, S., T. Sicular and B. Gustafsson (2008), Research on Income Distribution in China III, Beijing Normal University Publishing Group, Beijing.

Lin, J., (1992), “Rural Reforms and Agricultural Growth in China,” American Economic Review, 82, 34-51.

Lin, J., F. Cai, and Z. Li (1994), The Chinese Miracle: Development Strategy and Economic Reform, Shanghai Sanlin Publish House and Shanghai People's Publishing House, Shanghai.

Liu, Z. (2005), “Institution and Inequality: The Hukou System in China,” Journal of Comparative Economics 33(1)1, 133-157.

Machado, J. and J. Mata (2005), “Counterfactual decomposition of changes in wage distributions using quantile regression,” Journal of Applied Econometrics, 20, 445-465. 
Meng, X. (2003), “Unemployment, consumption smoothing, and precautionary saving in urban China,” Journal of Comparative Economics 31, 465-485.

National Bureau of Statistics of China (1989a), China Population Statistics Yearbook 1989, Science and Technology Literature Press, Beijing.

National Bureau of Statistics of China (1989b), China Statistics Yearbook 1989, China Statistics Press, Beijing.

National Bureau of Statistics of China (1996a), China Statistics Population Yearbook 1996, China Statistics Press, Beijing.

National Bureau of Statistics of China (1996b), China Statistics Yearbook 1996, China Statistics Press, Beijing.

National Bureau of Statistics of China (2001), China Statistics Yearbook 2001, China Statistics Press, Beijing.

National Bureau of Statistics of China (2003a), China Population Statistics Yearbooks 2003, China Statistics Press, Beijing.

National Bureau of Statistics of China (2003b), China Statistics Yearbook 2003, China Statistics Press, Beijing.

National Bureau of Statistics of China (2007), China Statistics Yearbook 2007, China Statistics Press, Beijing.

Nguyen, B. T., J. Albrecht, S. C. Vroman, and D. Westbrook (2007), “A quantile regression decomposition of urban-rural inequality in Vietnam,” Journal of Development Economics, 83, 466-490.

Oaxaca, R. (1973), "Male-female wage differentials in urban labor markets," International Economic Review, 14, 693-709.

Pisati, M (2007), “SPMAP: Stata module to visualize spatial data,” URL: http://econpapers.repec.org/software/bocbocode/s456812.htm. 
Ravallion, M. and S. Chen (2007), “China's (uneven) progress against poverty,” Journal of Development Economics 82, 1-42.

Skinner, G. W., M. Henderson, and Z. Yue (2007), “Physiographic Macroregions,” Davis: University of California, Regional Systems Analysis Project.

Tsui, K. (1993), “Decomposition of China's Regional Inequalities,” Journal of Comparative Economics, 17, 6000-627.

Wu, H. (1994), "Rural to Urban Migration in the People’s Republic of China," China Quarterly 139, 669-698.

Wu, X. and J. M. Perloff (2005), “China's income distribution, 1985-2001,” The Review of Economics and Statistics 87, 763-775.

Yue, Z., G. W. Skinner, and M. Henderson (2007), ChinaW Dataset, Davis: University of California, Regional Systems Analysis Project.

Zhao, R., K. Griffin, S. Li, and L. Zhu (1994), Studies of Income Distribution in China, Press of Chinese Social Sciences, Beijing.

Zhao, R., S. Li, and C. Riskin (1999), Re-studies of Income Distribution in China, China Economics and Finance Press, Beijing.

Zhao, Y. (1999), "Labor Migration and Earnings Differences: The Case of Rural China,” Economic Development and Cultural Change 47(4), 767-782.

Zhao, Y. (2000), "Rural-to-Urban Labor Migration in China: The Past and the Present," in Rural Labor Flows in China, eds. Loraine A. West and Yaohui Zhao, Institute of East Asian Studies, University of California, Berkeley.

Zhao, Z. (2005), “Migration, Labor Market Flexibility, and Wage Determination in China: A Review,” Developing Economies 43, 285-312. 


\section{Technical Appendix}

\section{Quantile Regression Decomposition}

This appendix is largely based on Machado and Mata (2005) and Autor, Katz, and Kearney (2005).

Let $Q_{\theta}(\ln y \mid x)$ for $\theta \in(0,1)$ denote the $\theta$ h quantile of the distribution of the log consumption given the vector $x$ of covariates. So the quantile regression equation is

$$
Q_{\theta}(\ln y \mid x)=x^{\prime} \beta(\theta)
$$

where $x$ is a $k \times 1$ vector of covariates and $\beta(\theta)$ is a vector of coefficients. We can estimate $\beta(\theta)$ by the following, as shown in the seminar paper of Koenker and Bassett (1978):

$$
\hat{\beta}_{\theta}=\arg \min _{\beta}\left\{\frac{1}{n}\left[\sum_{i: \ln y_{i} \geq x_{i} \beta} \theta\left|\ln y_{i}-x_{i} \beta\right|+\sum_{i: \ln y_{i}<x_{i} \beta}(1-\theta)\left|\ln y_{i}-x_{i} \beta\right|\right]\right\} \text {. (A2) }
$$

The main idea of Machado and Mata (2005) is the probability integral transformation, i.e., if $U$ is uniformly distributed over the interval $(0,1)$, then $V=F_{V}^{-1}(U)$ has cumulative distribution function $F_{V}(\cdot)$. So for a given $X_{i}$, if $\theta$ has a uniform distribution, then $x_{i} \beta(\theta)$ has the same distribution as the conditional distribution $y_{i} \mid X_{i}$, and $x \beta(\theta)$ has the same distribution as the unconditional distribution $y$ if $x$ is not given. Based on this idea, we can simulate the counterfactual distributions in the paper as follows:

(1) Draw $\theta_{1}, \theta_{2} \cdots, \theta_{l}$ from a uniform $(0,1)$ distribution. 
(2) For the rural sample, run quantile regressions at each $\theta_{i}, i=1, \ldots, l$, and get $l$ estimates of the quantile regression coefficients $\hat{\beta}_{r}\left(\theta_{i}\right)$, where $r$ represents rural sample. In our paper, we set $l=2,000$.

(3) Draw a random sample of size $l$ with replacement from the urban sample denoted by $\left\{x_{i}^{*}(u)\right\}, i=1, \ldots, l$, where $u$ represents urban sample.

(4) Combining (3) and (4), we have $\left\{\ln y_{i}^{*}(u \cdot r)\right\} \equiv\left\{x_{i}^{*}(u)\right\}^{\prime} \cdot \hat{\beta}_{r}\left(\theta_{i}\right)$, which is the counterfactual consumption distribution that the rural households would have if they had the same endowment as their counterpart urban households.

(1) Following the same procedure, we can generate another counterfactual distribution, $\left\{\ln y_{i}^{*}(r \cdot u)\right\} \equiv\left\{x_{i}^{*}(r)\right\}^{\prime} \cdot \hat{\beta}_{u}\left(\theta_{i}\right)$, which is the consumption distribution the rural households would have if their endowments received the same prices as their urban counterparts. 


\section{Table 1. Estimated Urban-Rural Gap at the Mean and Quantiles}

\begin{tabular}{|c|c|c|c|c|c|c|}
\hline \multicolumn{7}{|c|}{ Dependent Variable: log of consumption expenditure } \\
\hline & OLS & 5th & 25th & 50th & 75th & 95th \\
\hline \multicolumn{7}{|c|}{ Panel A: 1988} \\
\hline Urban & $0.435^{* * *}$ & $0.604 * * *$ & $0.466 * * *$ & $0.404 * * *$ & $0.388 * * *$ & $0.317^{* * *}$ \\
\hline Shanxi & $-0.438 * * *$ & $-0.433 * * *$ & $-0.475^{* * *}$ & $-0.434 * * *$ & $-0.399 * * *$ & $-0.308^{* * *}$ \\
\hline Liaoning & $-0.295 * * *$ & $-0.275^{* * *}$ & $-0.282 * * *$ & $-0.304 * * *$ & $-0.270^{* * *}$ & $-0.283^{* * *}$ \\
\hline Jiangsu & $0.059 * * *$ & $0.168 * * *$ & $0.091 * * *$ & $0.062 * * *$ & $0.0486 * *$ & 0.0161 \\
\hline Anhui & $-0.191 * * *$ & -0.049 & $-0.169 * * *$ & $-0.211^{* * *}$ & $-0.197 * * *$ & $-0.217^{* * *}$ \\
\hline Henan & $-0.276 * * *$ & $-0.195 * * *$ & $-0.259 * * *$ & $-0.287 * * *$ & $-0.285 * * *$ & $-0.257 * * *$ \\
\hline Hubei & 0.009 & $0.076^{*}$ & $0.047 * *$ & 0.007 & $-0.060^{* *}$ & -0.009 \\
\hline Guangdong & $0.221^{* * *}$ & $0.222 * * *$ & $0.256^{* * *}$ & $0.243^{* * *}$ & $0.245^{* * *}$ & $0.167 * * *$ \\
\hline Yunnan & $0.024^{*}$ & 0.018 & $0.063 * * *$ & 0.0286 & 0.036 & 0.039 \\
\hline Gansu & $-0.164 * * *$ & $-0.259 * * *$ & $-0.215^{* * *}$ & $-0.145^{* * *}$ & -0.06 & -0.011 \\
\hline Constant & $6.055 * * *$ & $5.316 * * *$ & $5.800 * * *$ & $6.088 * * *$ & $6.301 * * *$ & $6.678 * * *$ \\
\hline No. of obs. & 10127 & 10127 & 10127 & 10127 & 10127 & 10127 \\
\hline Adj. $R^{2}$ & 0.29 & & & & & \\
\hline \multicolumn{7}{|c|}{ Panel B: 1995} \\
\hline Urban & $1.105^{* * *}$ & $1.191^{* * *}$ & $1.111^{* * *}$ & $1.087 * * *$ & $1.101^{* * *}$ & $1.044^{* * *}$ \\
\hline Shanxi & $-0.646 * * *$ & $-0.584 * * *$ & $-0.673 * * *$ & $-0.636^{* * *}$ & $-0.628 * * *$ & $-0.595^{* * *}$ \\
\hline Liaoning & $-0.398 * * *$ & $-0.457 * * *$ & $-0.470 * * *$ & $-0.370 * * *$ & $-0.333^{* * *}$ & $-0.378 * * *$ \\
\hline Jiangsu & $-0.182 * * *$ & $-0.228 * * *$ & $-0.255^{* * *}$ & $-0.165^{* * *}$ & $-0.114^{* *}$ & $-0.107 *$ \\
\hline Anhui & $-0.448 * * *$ & $-0.399 * * *$ & $-0.493 * * *$ & $-0.435^{* * *}$ & $-0.457 * * *$ & $-0.359 * * *$ \\
\hline Henan & $-0.448 * * *$ & $-0.438 * * *$ & $-0.504^{* * *}$ & $-0.437 * * *$ & $-0.413^{* * *}$ & $-0.367 * * *$ \\
\hline Hubei & $-0.389 * * *$ & $-0.265^{* * *}$ & $-0.457 * * *$ & $-0.360 * * *$ & $-0.373^{* * *}$ & $-0.388^{* * *}$ \\
\hline Guangdong & $0.170^{* * *}$ & $0.183^{* * *}$ & $0.158^{* * *}$ & $0.195 * * *$ & $0.187 * * *$ & $0.184^{* * *}$ \\
\hline Yunnan & $-0.384 * * *$ & $-0.283^{* * *}$ & $-0.415^{* * *}$ & $-0.351 * * *$ & $-0.387 * * *$ & $-0.465 * * *$ \\
\hline Gansu & $-0.599 * * *$ & $-0.543 * * *$ & $-0.608 * * *$ & $-0.587 * * *$ & $-0.617 * * *$ & $-0.588 * * *$ \\
\hline Constant & $6.715^{* * *}$ & $5.965^{* * *}$ & $6.489 * * *$ & $6.709^{* * *}$ & $6.960 * * *$ & $7.377^{* * *}$ \\
\hline No. of obs. & 4802 & 4802 & 4802 & 4802 & 4802 & 4802 \\
\hline Adj. $R^{2}$ & 0.605 & & & & & \\
\hline \multicolumn{7}{|c|}{ Panel C: 2002} \\
\hline Urban & $1.335^{* * *}$ & $1.318^{* * *}$ & $1.398 * * *$ & $1.382 * * *$ & $1.286^{* * *}$ & $1.176^{* * *}$ \\
\hline Shanxi & $-0.373^{* * *}$ & $-0.360 * * *$ & $-0.373^{* * *}$ & $-0.386^{* * *}$ & $-0.427 * * *$ & $-0.207 * * *$ \\
\hline Liaoning & $-0.128 * * *$ & $-0.152^{* * *}$ & $-0.076^{* *}$ & $-0.130 * * *$ & $-0.205^{* * *}$ & $-0.111^{* *}$ \\
\hline Jiangsu & $-0.139 * * *$ & $-0.214 * * *$ & $-0.093 * *$ & $-0.159 * * *$ & $-0.192 * * *$ & $-0.094 * *$ \\
\hline Anhui & $-0.341 * * *$ & $-0.286^{* * *}$ & $-0.285^{* * *}$ & $-0.369 * * *$ & $-0.425^{* * *}$ & $-0.249 * * *$ \\
\hline Henan & $-0.271^{* * *}$ & $-0.302 * * *$ & $-0.264 * * *$ & $-0.286^{* * *}$ & $-0.299 * * *$ & $-0.160 * * *$ \\
\hline Hubei & $-0.233 * * *$ & $-0.225 * * *$ & $-0.179 * * *$ & $-0.239 * * *$ & $-0.306 * * *$ & $-0.190 * * *$ \\
\hline Guangdong & $0.287 * * *$ & $0.253^{* * *}$ & $0.359 * * *$ & $0.302 * * *$ & $0.216^{* * *}$ & $0.188 * * *$ \\
\hline Yunnan & $-0.266 * * *$ & $-0.234^{* * *}$ & $-0.230 * * *$ & $-0.298 * * *$ & $-0.313^{* * *}$ & $-0.219 * * *$ \\
\hline Gansu & $-0.462 * * *$ & $-0.440 * * *$ & $-0.450 * * *$ & $-0.484 * * *$ & $-0.516^{* * *}$ & $-0.472 * * *$ \\
\hline Constant & $6.501^{* * *}$ & $5.783^{* * *}$ & $6.113^{* * *}$ & $6.475^{* * *}$ & $6.899 * * *$ & $7.307 * * *$ \\
\hline No. of obs. & 7972 & 7972 & 7972 & 7972 & 7972 & 7972 \\
\hline Adj. $R^{2}$ & 0.607 & & & & & \\
\hline
\end{tabular}

Note: 1 . Omitted province is Beijing;

2. $* * *, * *$, and $*$ stand for significant at $1 \%, 5 \%$, and $10 \%$ levels, respectively;

3. Standard errors are available upon request. 
Table 2. Blinder-Oaxaca Decompositions of Urban-Rural Gap

\begin{tabular}{|c|c|c|c|c|c|c|}
\hline & \multicolumn{2}{|c|}{1988} & \multicolumn{2}{|c|}{1995} & \multicolumn{2}{|c|}{2002} \\
\hline & Coef. & Std. Err. & Coef. & Std. Err. & Coef. & Std. Err. \\
\hline \multicolumn{7}{|l|}{ Panel A: Consumption } \\
\hline \multicolumn{7}{|l|}{ Differential } \\
\hline Prediction for urban & 6.3742 & 0.0006 & 7.4305 & 0.0012 & 7.5834 & 0.0010 \\
\hline Prediction for rural & 5.9386 & 0.0024 & 6.4655 & 0.0027 & 6.3415 & 0.0021 \\
\hline Difference & 0.4356 & 0.0025 & 0.9650 & 0.0030 & 1.2419 & 0.0024 \\
\hline \multicolumn{7}{|l|}{ Decomposition } \\
\hline Endowments & 0.0737 & 0.0038 & 0.1240 & 0.0069 & 0.3459 & 0.0081 \\
\hline Explained percentage & $16.92 \%$ & & $12.85 \%$ & & $27.85 \%$ & \\
\hline Coefficients & 0.2807 & 0.0022 & 0.7695 & 0.0032 & 1.0316 & 0.0041 \\
\hline Explained percentage & $64.44 \%$ & & $79.74 \%$ & & $83.07 \%$ & \\
\hline Interaction & 0.0811 & 0.0036 & 0.0715 & 0.0070 & -0.1356 & 0.0088 \\
\hline Explained percentage & $18.62 \%$ & & $7.41 \%$ & & $-10.92 \%$ & \\
\hline \multicolumn{7}{|l|}{ Panel B: Income } \\
\hline \multicolumn{7}{|l|}{ Differential } \\
\hline Prediction for urban & 7.1182 & 0.0006 & 7.6529 & 0.0013 & 8.0045 & 0.0011 \\
\hline Prediction for rural & 6.4556 & 0.0026 & 6.9515 & 0.003 & 7.0658 & 0.0023 \\
\hline Difference & 0.6625 & 0.0027 & 0.7014 & 0.0032 & 0.9388 & 0.0026 \\
\hline \multicolumn{7}{|l|}{ Decomposition } \\
\hline Endowments & 0.0316 & 0.0041 & 0.1113 & 0.0076 & 0.3777 & 0.0089 \\
\hline Explained percentage & $4.77 \%$ & & $15.87 \%$ & & $40.23 \%$ & \\
\hline Coefficients & 0.4906 & 0.0024 & 0.5031 & 0.0033 & 0.7119 & 0.0042 \\
\hline Explained percentage & $74.05 \%$ & & $71.73 \%$ & & $75.83 \%$ & \\
\hline Interaction & 0.1403 & 0.0039 & 0.087 & 0.0076 & -0.1508 & 0.0095 \\
\hline Explained percentage & $21.18 \%$ & & $12.40 \%$ & & $-16.06 \%$ & \\
\hline
\end{tabular}


Figure 1. Urban-Rural Income Ratio

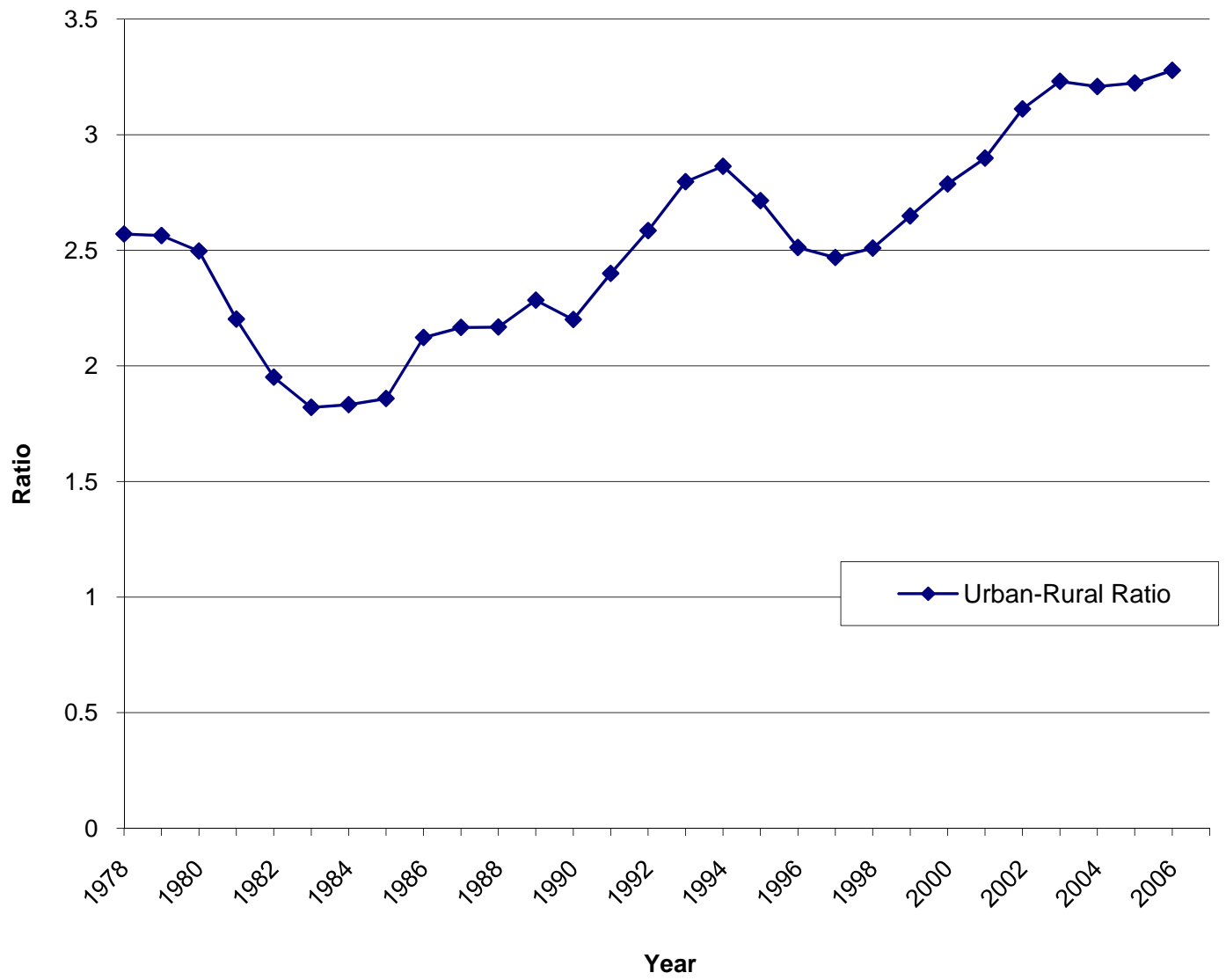

Source: Table 10-3 in NBS (2001) and Table 10-2 in NBS (2007). 
Figure 2. Kernel Densities of Consumption, Food Consumption, and Income

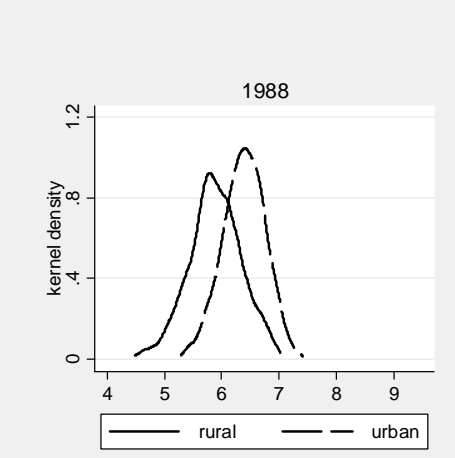

\section{Panel A. Consumption}
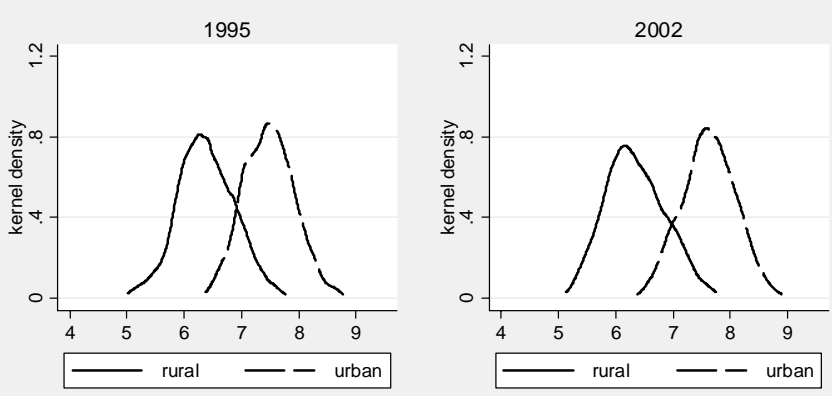

Panel B. Food Consumption
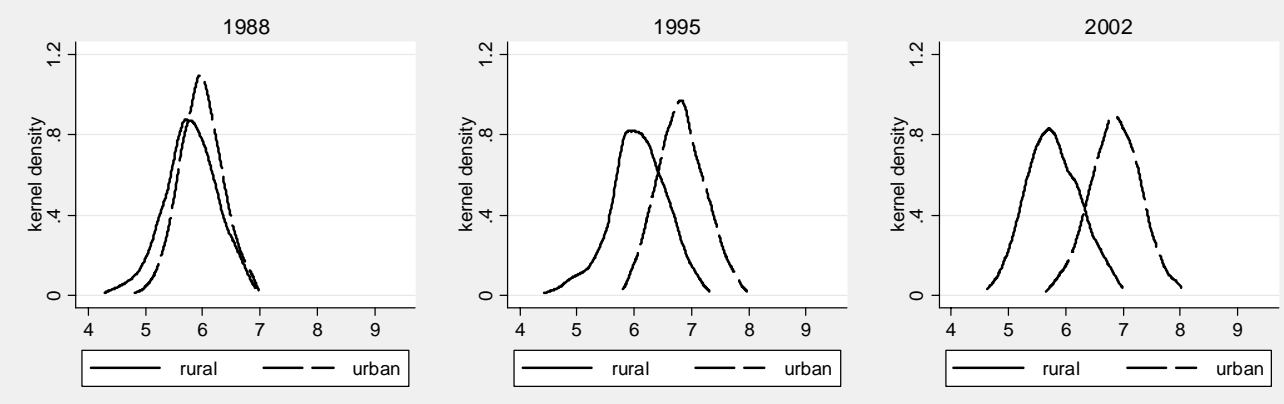

Panel C. Augmented Consumption
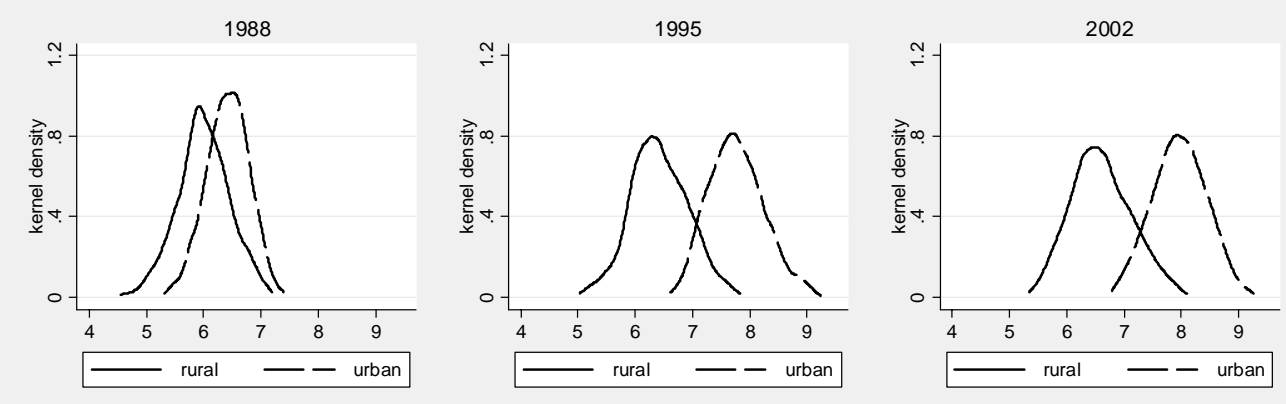

Panel D. Total Income
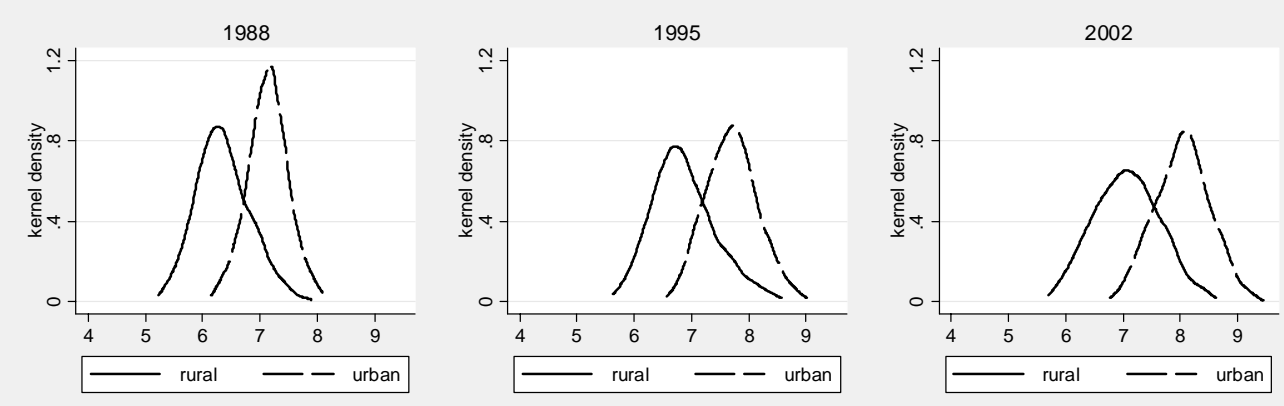
Figure 3. Urban-Rural Gap in Quantiles
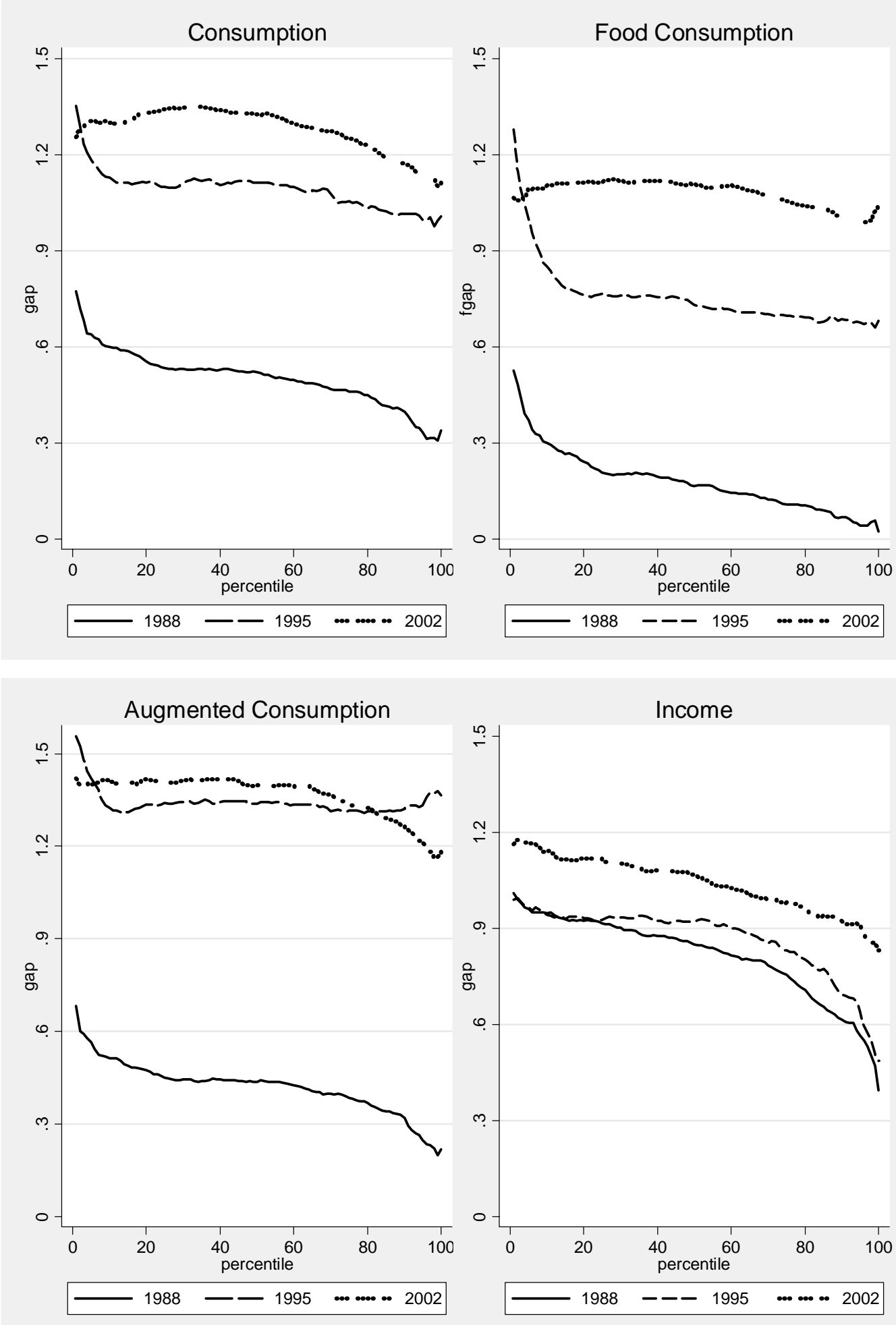
Figure 4. Quantile Decompositions for Urban-Rural Gap by Year

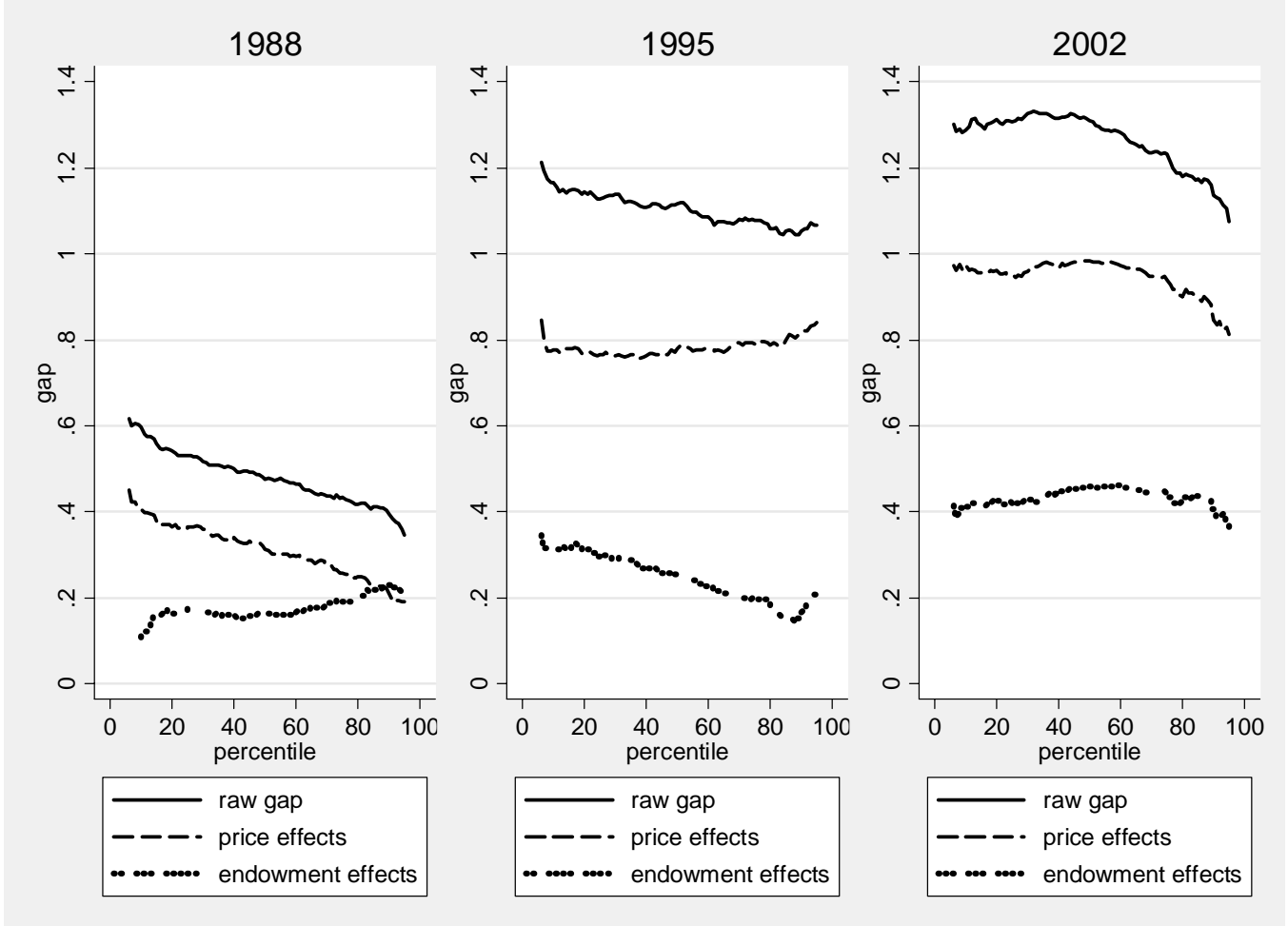


Figure 5. Price and Endowment Effects of Education

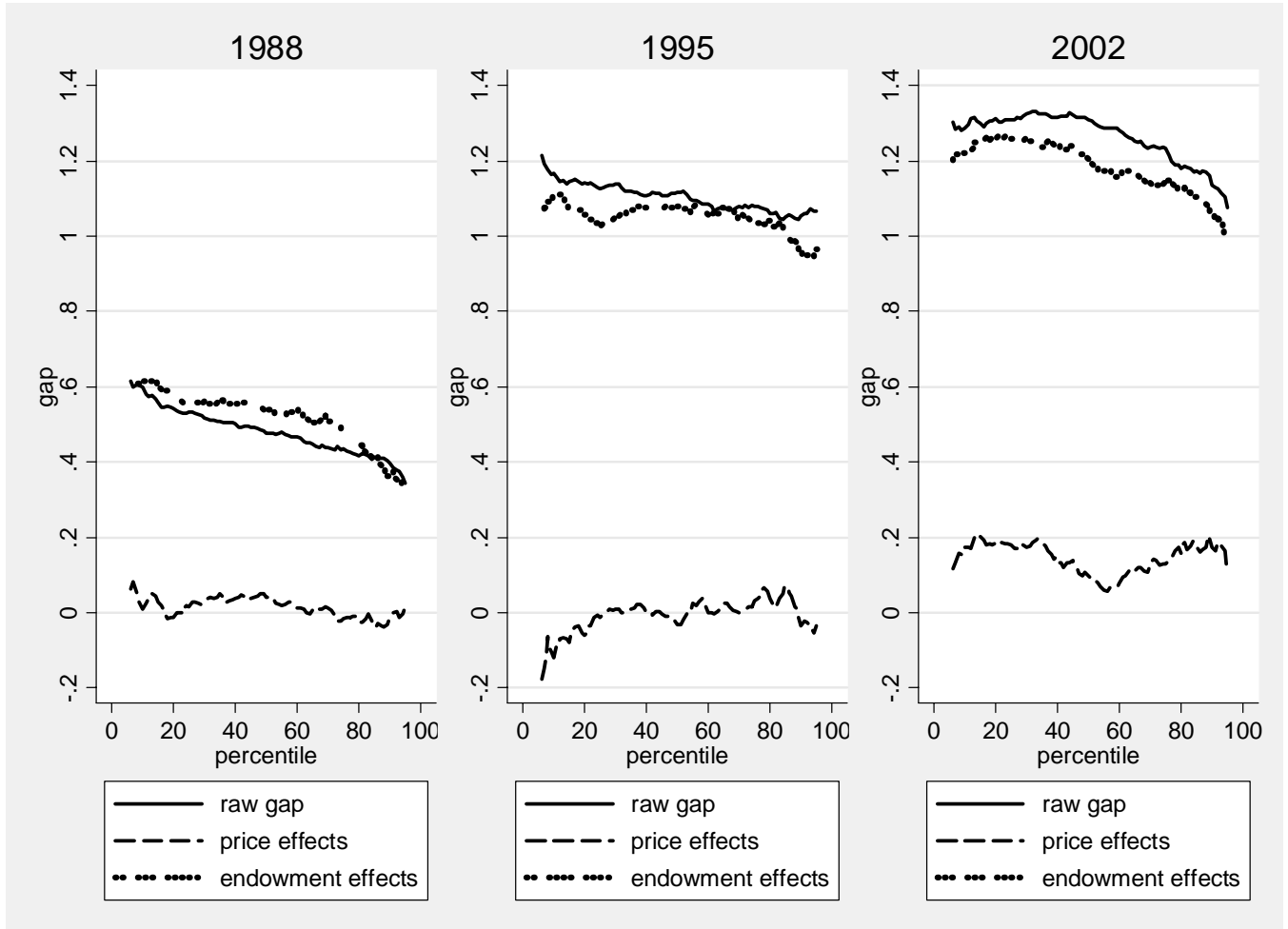


Figure 6. Quantile Decompositions with Migrant Sample in 2002

Panel A. Decomposition by Legal Status

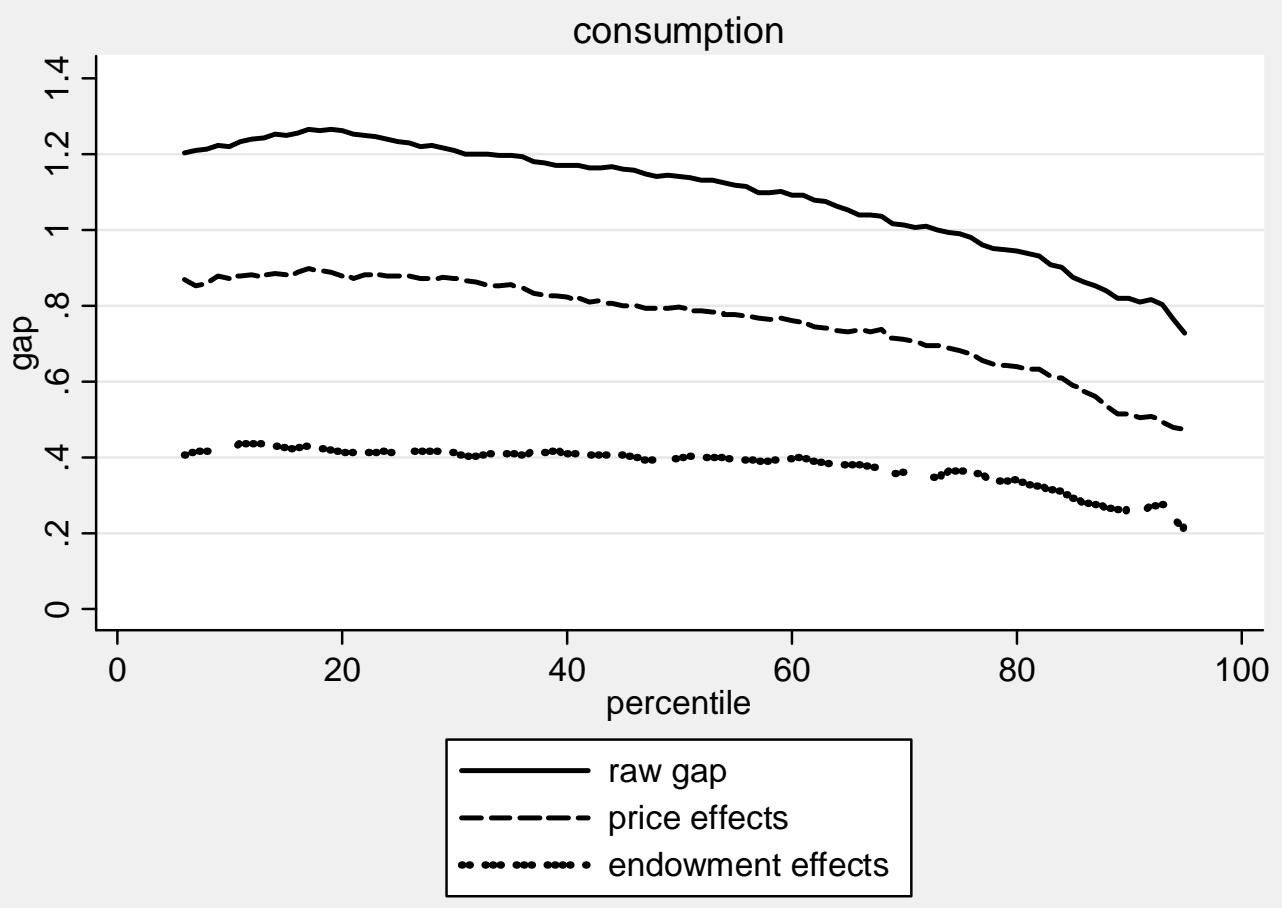

Panel B. Decomposition by Residence

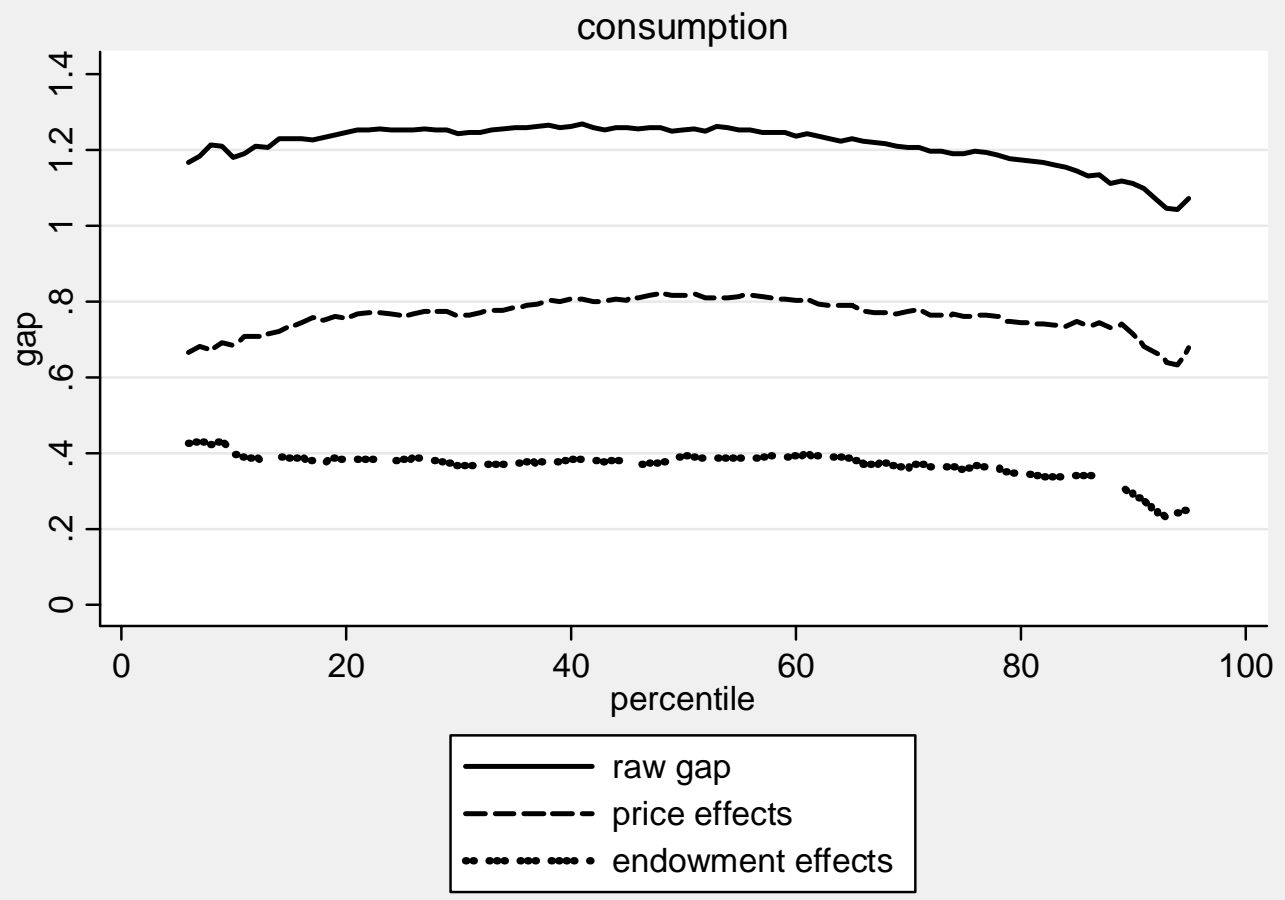


Figure 7. Quantile Decompositions over Time by Urban and Rural Areas

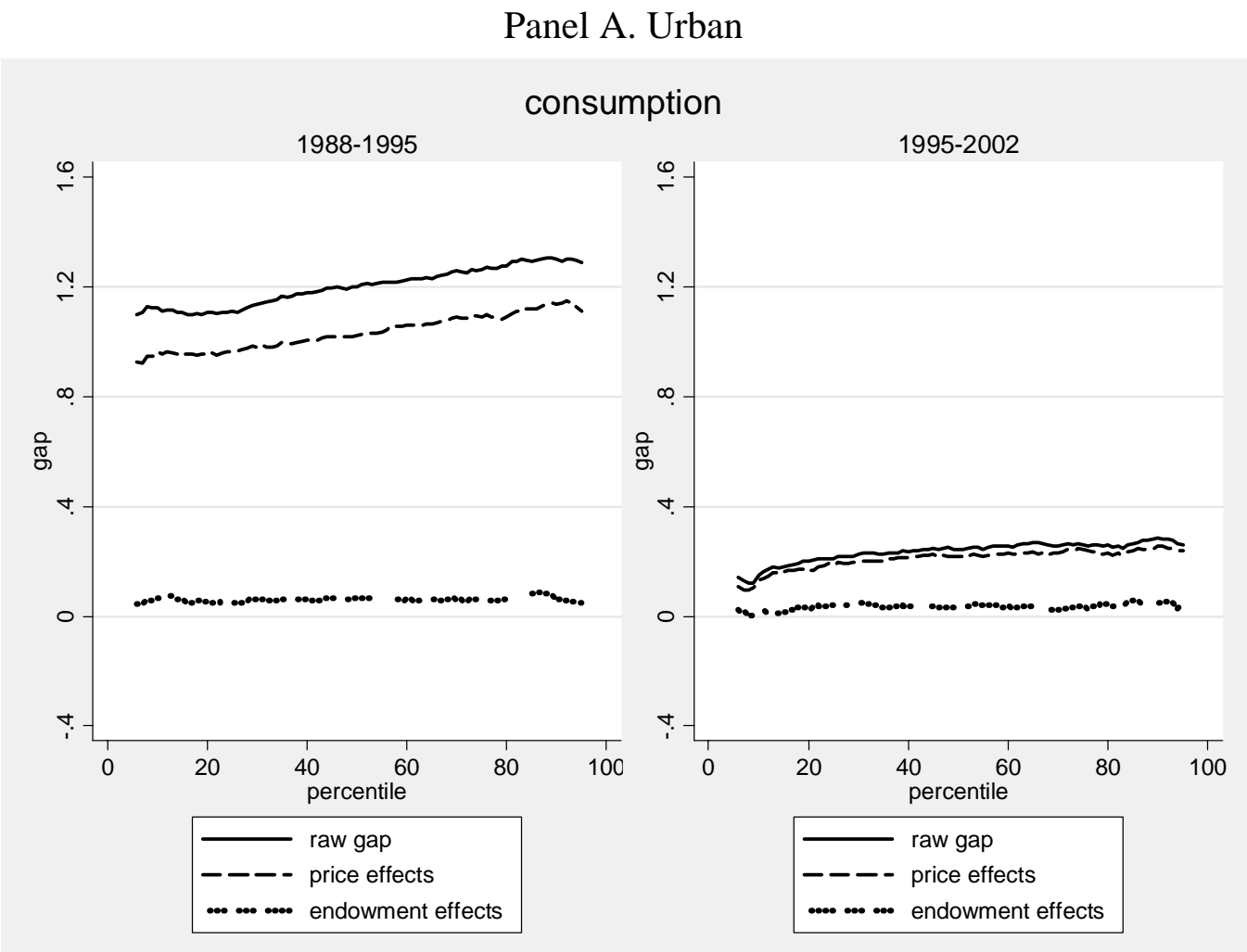

Panel B. Rural

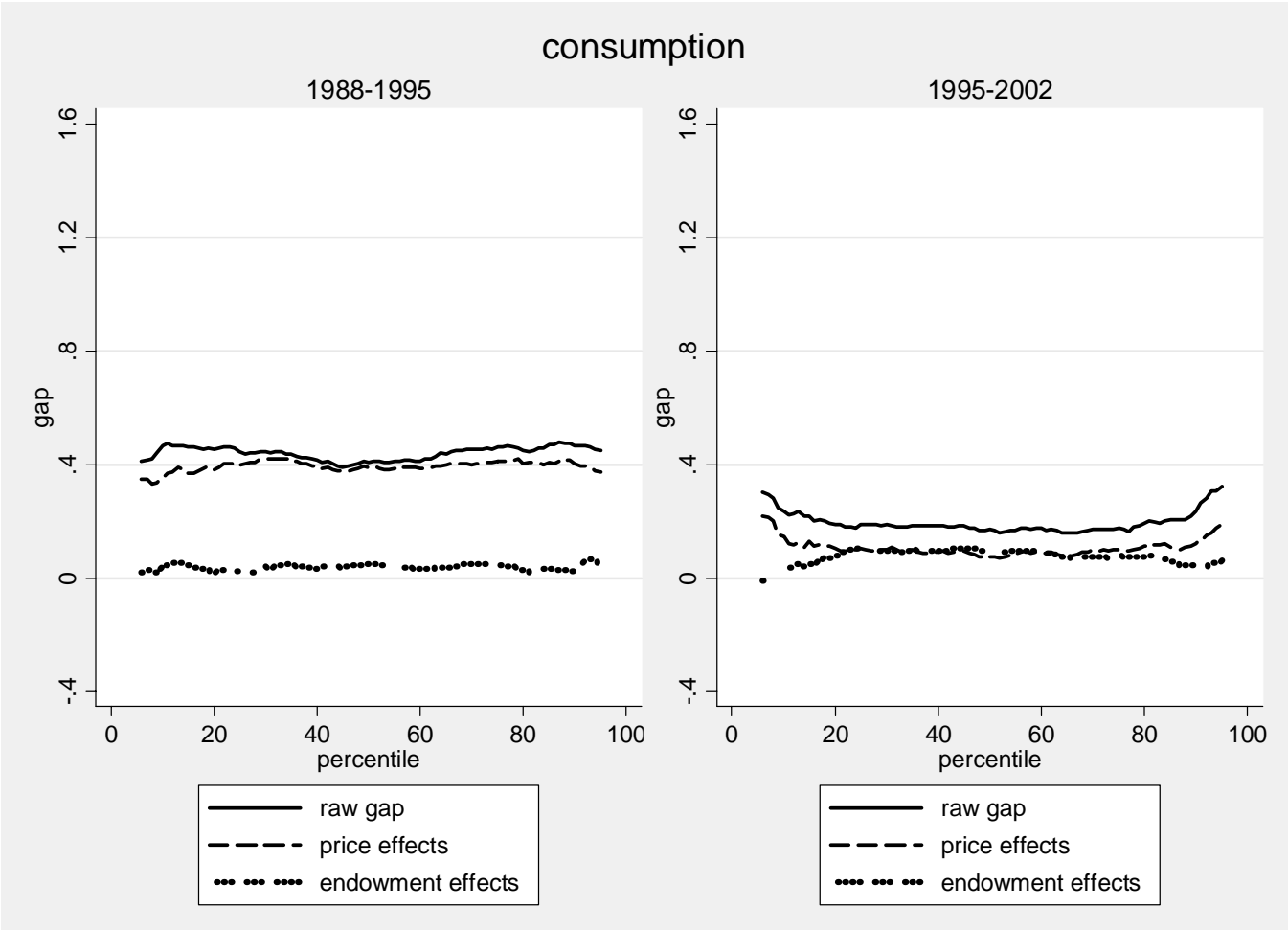


Figure 8. Quantile Decompositions with OECD-modified Equivalence Scale Adjustment

Panel A. Urban-Rural Decompositions by Year

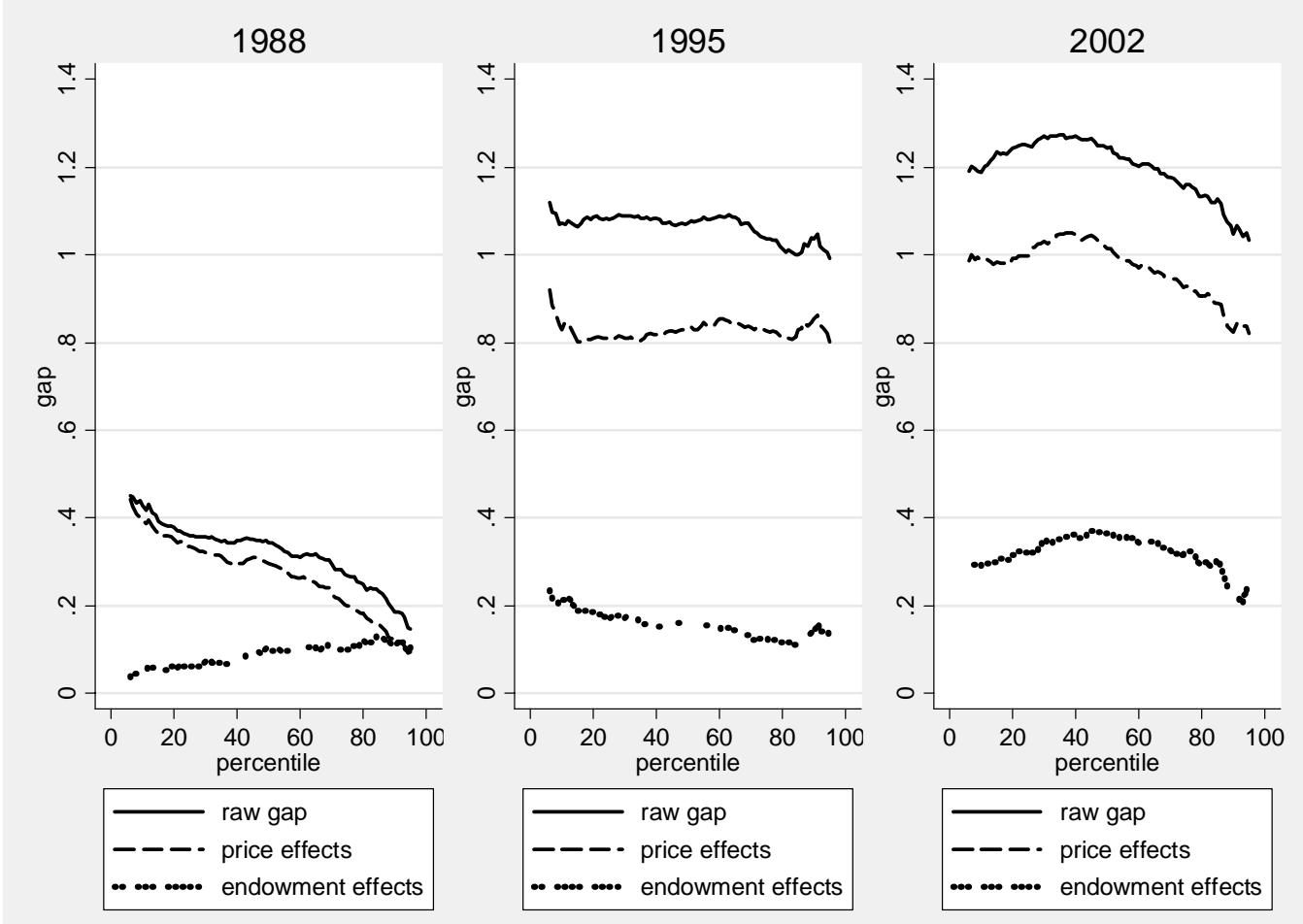

Panel B. Decompositions over Time by Urban and Rural Areas

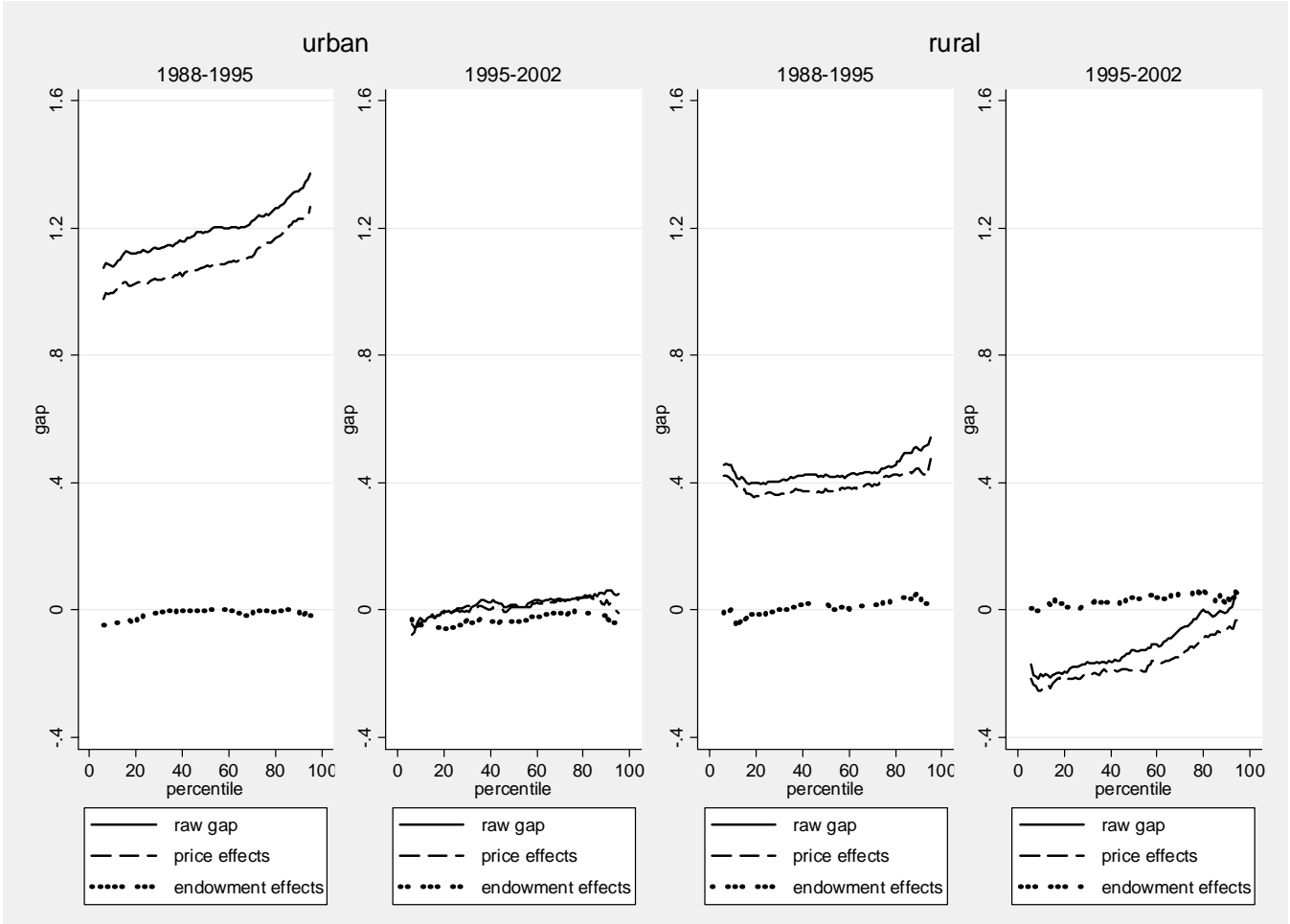


Figure 9. Decompositions Using Price Index of Brandt and Holz (2006)

Panel A. Urban-Rural Decompositions by Year

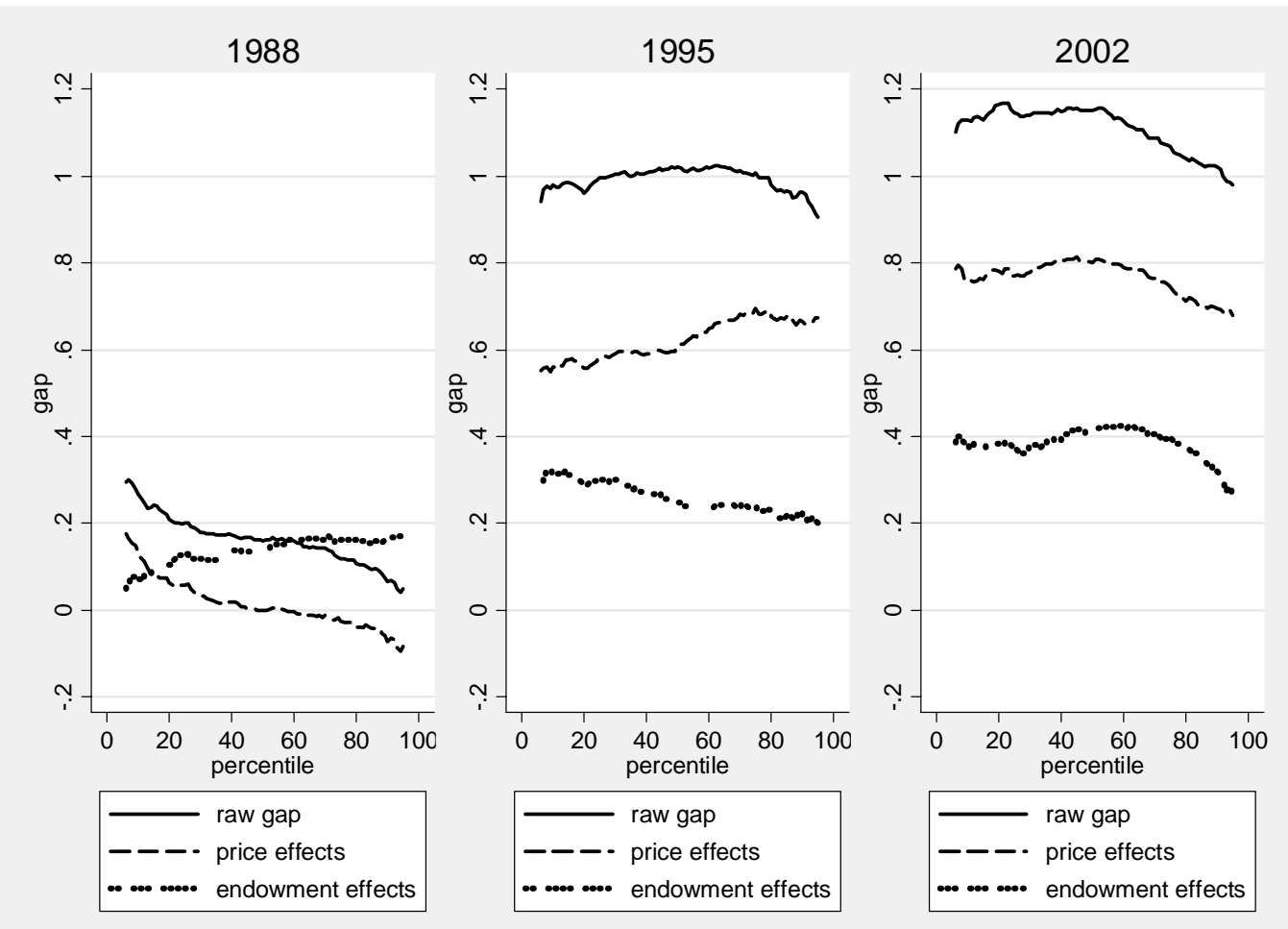

Panel B. Decompositions over Time by Urban and Rural Areas

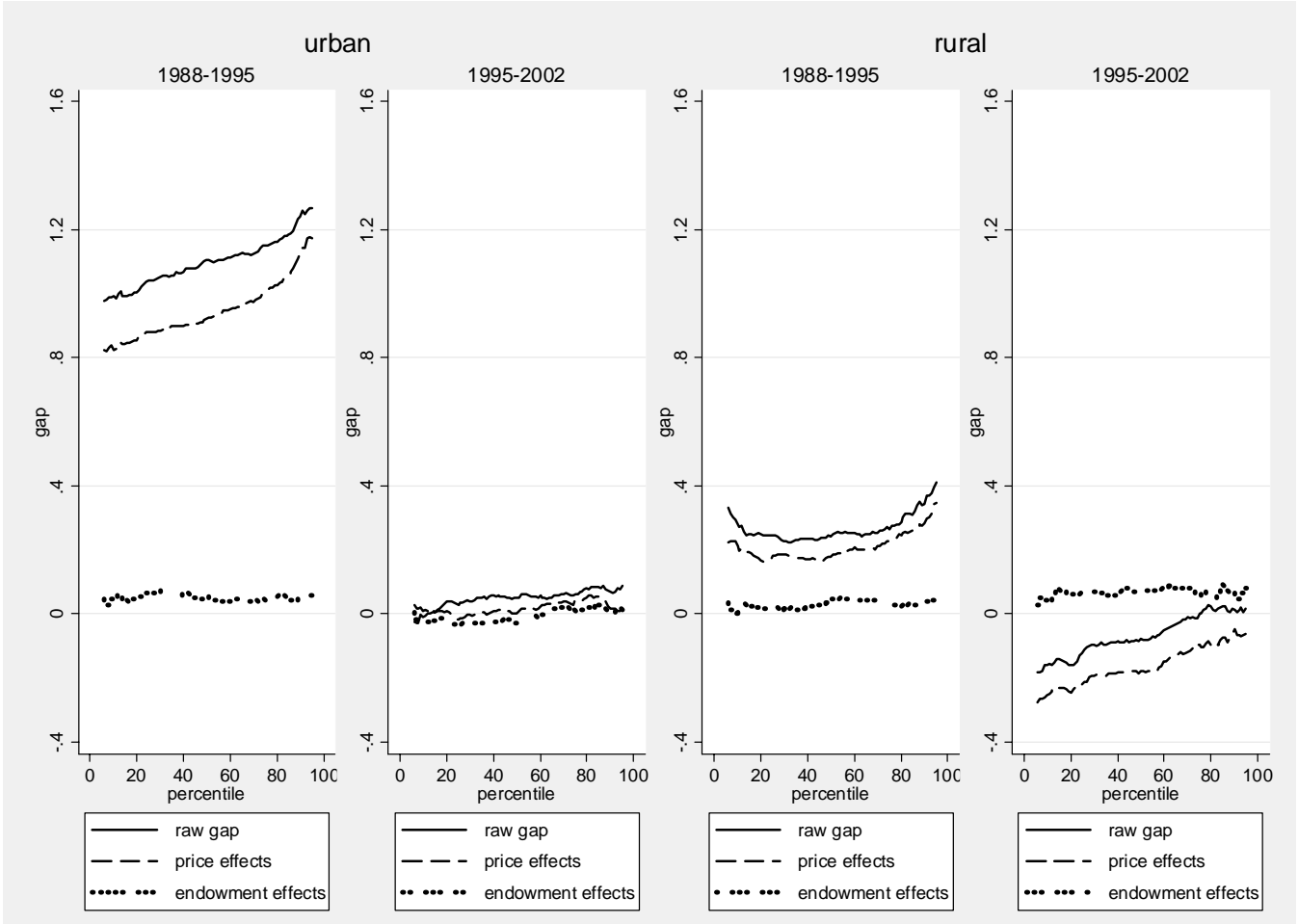




\section{Figure 10. Quantile Decompositions for Augmented Consumption}

Panel A. Urban-Rural Decompositions by Year

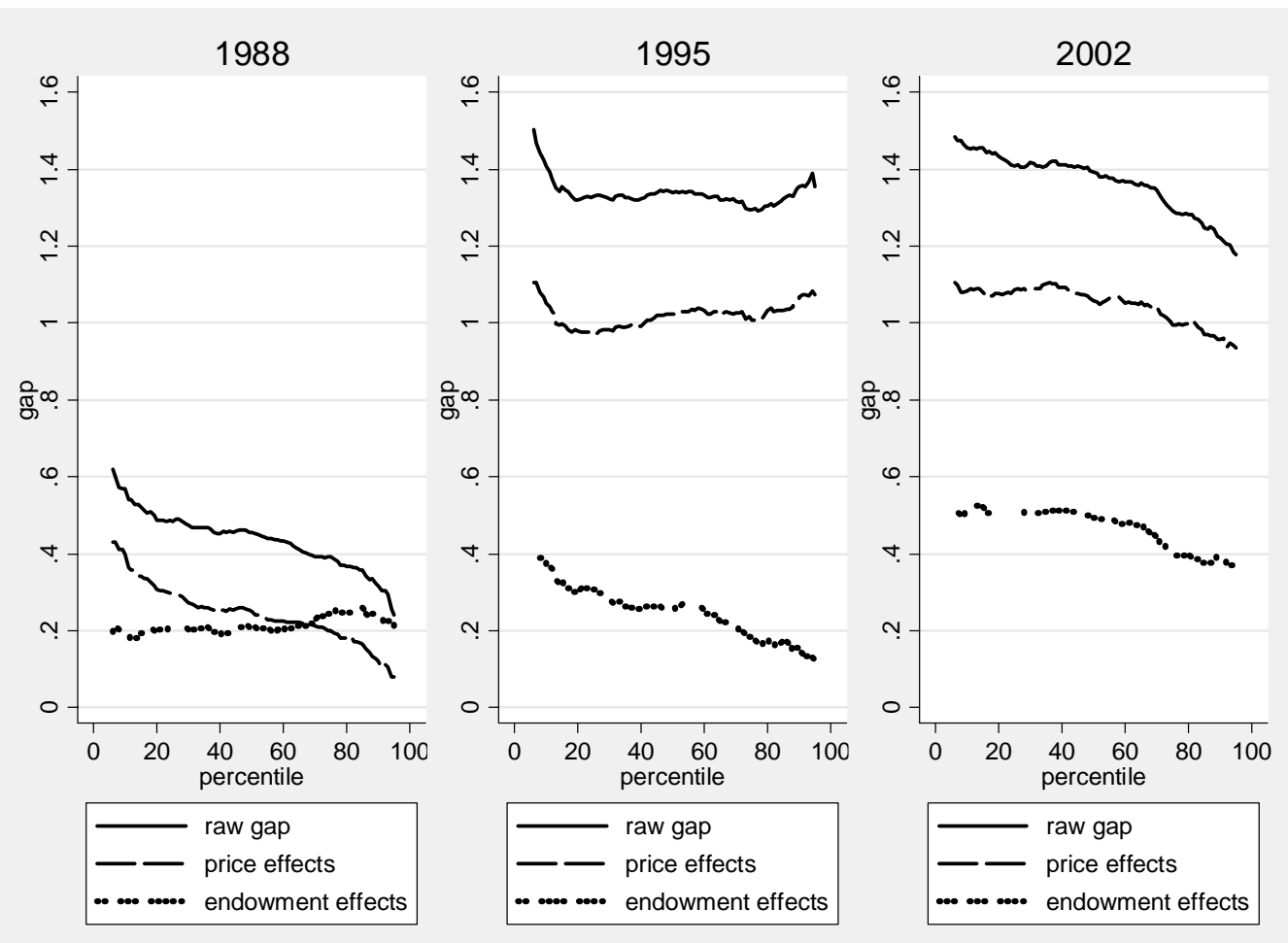

Panel B. Decompositions over Time by Urban and Rural Areas

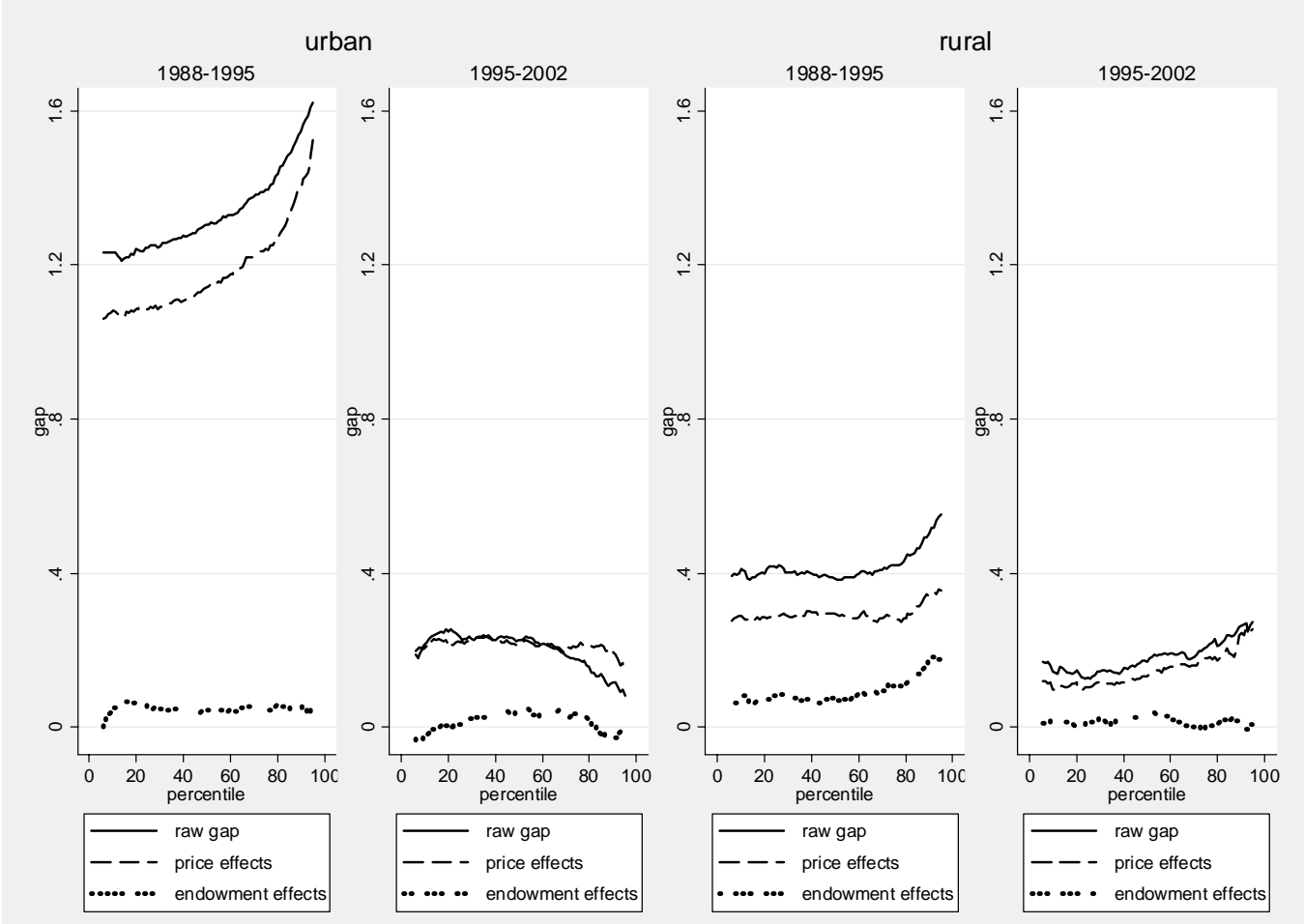




\section{Figure 11. Food Expenditure}

Panel A. Urban-Rural Decompositions by Year

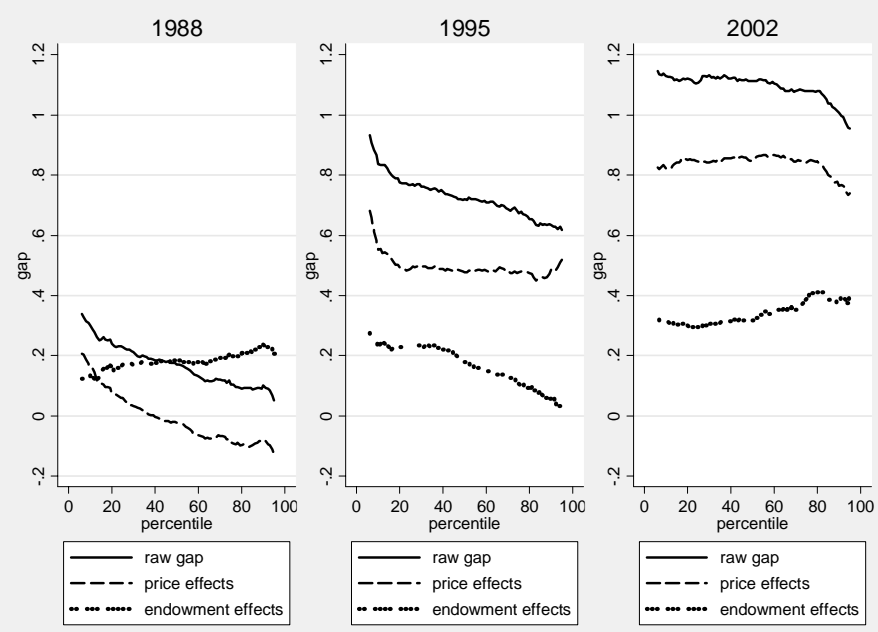

Panel B. Decompositions over Time by Urban and Rural Areas

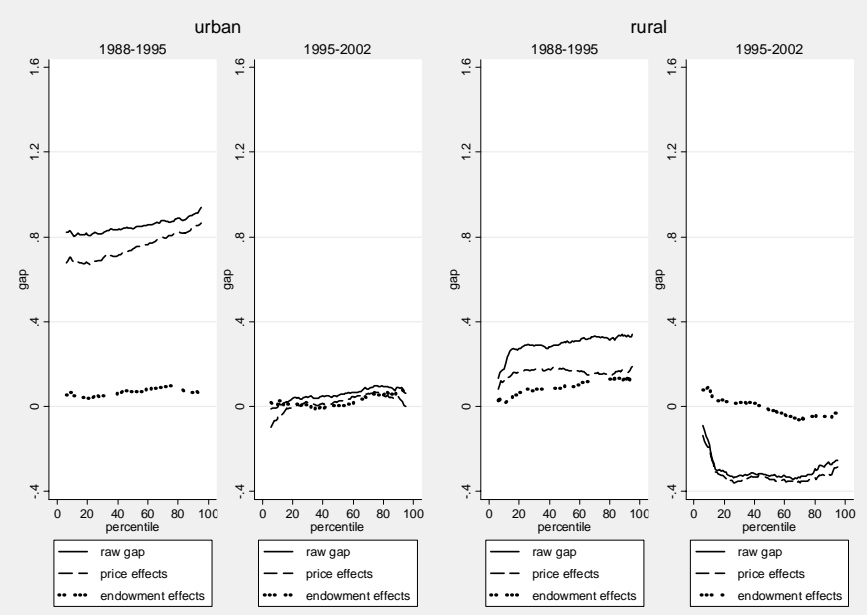

Panel C. Impact of Migration

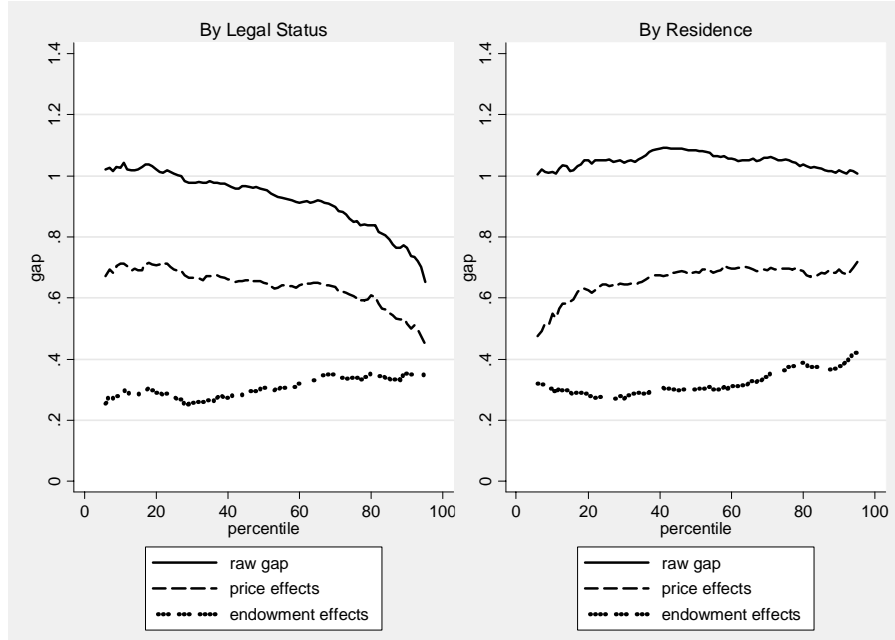




\section{Appendix Tables and Figures}

Table A1. Descriptive Statistics for 1988

\begin{tabular}{|c|c|c|c|c|c|c|c|c|}
\hline \multirow[b]{3}{*}{ Variable } & \multicolumn{4}{|c|}{ Rural } & \multicolumn{4}{|c|}{ Urban } \\
\hline & \multicolumn{2}{|c|}{ Nonweighted } & \multicolumn{2}{|c|}{ Weighted } & \multicolumn{2}{|c|}{ Nonweighted } & \multicolumn{2}{|c|}{ Weighted } \\
\hline & Mean & Std. Dev. & Mean & Std. Dev. & Mean & Std. Dev. & Mean & Std. Dev. \\
\hline $\begin{array}{l}\text { Log } \\
\text { Consumption }\end{array}$ & 5.886 & 0.455 & 5.938 & 0.454 & 6.388 & 0.372 & 6.374 & 0.378 \\
\hline $\begin{array}{l}\text { Log augmented } \\
\text { Consumption }\end{array}$ & 5.996 & 0.455 & 6.05 & 0.453 & 6.417 & 0.374 & 6.402 & 0.379 \\
\hline $\begin{array}{l}\text { Log food } \\
\text { Consumption }\end{array}$ & 5.792 & 0.468 & 5.837 & 0.466 & 5.97 & 0.377 & 5.946 & 0.374 \\
\hline Log total income & 6.428 & 0.476 & 6.521 & 0.5 & 7.242 & 0.352 & 7.223 & 0.355 \\
\hline $\begin{array}{l}\text { Age of } \\
\text { household head }\end{array}$ & 43.128 & 10.728 & 43.175 & 10.646 & 43.322 & 10.815 & 43.661 & 10.842 \\
\hline Family size & 5.076 & 1.688 & 4.838 & 1.621 & 3.556 & 1.004 & 3.577 & 1.008 \\
\hline Share of children & 0.275 & 0.2 & 0.271 & 0.198 & 0.223 & 0.177 & 0.224 & 0.179 \\
\hline Male & 0.943 & 0.233 & 0.937 & 0.243 & 0.923 & 0.267 & 0.926 & 0.261 \\
\hline Education & 6.691 & 3.647 & 6.864 & 3.425 & 8.194 & 3.562 & 8.159 & 3.607 \\
\hline Ethnicity & 0.065 & 0.247 & 0.073 & 0.261 & 0.039 & 0.194 & 0.052 & 0.222 \\
\hline Party membership & 0.15 & 0.357 & 0.178 & 0.382 & 0.39 & 0.488 & 0.405 & 0.491 \\
\hline $\begin{array}{l}\text { Unemployed or } \\
\text { out of labor force }\end{array}$ & 0.015 & 0.123 & 0.019 & 0.138 & 0.004 & 0.061 & 0.005 & 0.069 \\
\hline Employed & 0.979 & 0.143 & 0.975 & 0.155 & 0.924 & 0.265 & 0.918 & 0.275 \\
\hline Retired & 0.005 & 0.074 & 0.005 & 0.073 & 0.073 & 0.259 & 0.078 & 0.267 \\
\hline Beijing & 0.036 & 0.186 & 0.254 & 0.436 & 0.054 & 0.225 & 0.068 & 0.253 \\
\hline Shanxi & 0.082 & 0.275 & 0.106 & 0.308 & 0.101 & 0.301 & 0.134 & 0.34 \\
\hline Liaoning & 0.104 & 0.306 & 0.129 & 0.335 & 0.106 & 0.307 & 0.052 & 0.222 \\
\hline Jiangsu & 0.145 & 0.352 & 0.077 & 0.267 & 0.142 & 0.349 & 0.087 & 0.281 \\
\hline Anhui & 0.149 & 0.356 & 0.09 & 0.286 & 0.094 & 0.292 & 0.091 & 0.288 \\
\hline Henan & 0.159 & 0.366 & 0.062 & 0.241 & 0.113 & 0.317 & 0.088 & 0.283 \\
\hline Hubei & 0.117 & 0.322 & 0.081 & 0.273 & 0.117 & 0.322 & 0.08 & 0.271 \\
\hline Guangdong & 0.073 & 0.26 & 0.044 & 0.205 & 0.1 & 0.3 & 0.057 & 0.232 \\
\hline Yunnan & 0.074 & 0.261 & 0.064 & 0.246 & 0.11 & 0.313 & 0.199 & 0.399 \\
\hline Gansu & 0.061 & 0.239 & 0.093 & 0.291 & 0.064 & 0.244 & 0.145 & 0.352 \\
\hline Number of obs. & & 21 & & & & 79 & & \\
\hline
\end{tabular}


Table A2. Descriptive Statistics for 1995

\begin{tabular}{|c|c|c|c|c|c|c|c|c|}
\hline \multirow[b]{3}{*}{ Variable } & \multicolumn{4}{|c|}{ Rural } & \multicolumn{4}{|c|}{ Urban } \\
\hline & \multicolumn{2}{|c|}{ Nonweighted } & \multicolumn{2}{|c|}{ Weighted } & \multicolumn{2}{|c|}{ Nonweighted } & \multicolumn{2}{|c|}{ Weighted } \\
\hline & Mean & Std. Dev. & Mean & Std. Dev. & Mean & Std. Dev. & Mean & Std. Dev. \\
\hline $\begin{array}{l}\text { Log } \\
\text { Consumption }\end{array}$ & 6.386 & 0.493 & 6.463 & 0.522 & 7.479 & 0.44 & 7.431 & 0.417 \\
\hline $\begin{array}{l}\text { Log augmented } \\
\text { Consumption }\end{array}$ & 6.424 & 0.5 & 6.517 & 0.537 & 7.765 & 0.483 & 7.716 & 0.465 \\
\hline $\begin{array}{l}\text { Log food } \\
\text { Consumption }\end{array}$ & 6.068 & 0.497 & 6.083 & 0.493 & 6.823 & 0.414 & 6.781 & 0.39 \\
\hline Log total income & 6.864 & 0.553 & 6.949 & 0.57 & 7.731 & 0.453 & 7.682 & 0.433 \\
\hline $\begin{array}{l}\text { Age of } \\
\text { household head }\end{array}$ & 44.582 & 10.384 & 45.225 & 10.498 & 46.276 & 11.333 & 45.961 & 11.307 \\
\hline Family size & 4.406 & 1.291 & 4.273 & 1.233 & 3.17 & 0.82 & 3.156 & 0.8 \\
\hline Share of children & 0.238 & 0.21 & 0.219 & 0.206 & 0.168 & 0.169 & 0.174 & 0.17 \\
\hline Male & 0.948 & 0.222 & 0.877 & 0.328 & 0.687 & 0.464 & 0.679 & 0.467 \\
\hline Education & 6.458 & 2.918 & 6.868 & 3.054 & 10.597 & 3.313 & 10.626 & 3.264 \\
\hline Ethnicity & 0.041 & 0.199 & 0.047 & 0.211 & 0.043 & 0.202 & 0.062 & 0.241 \\
\hline $\begin{array}{l}\text { Party } \\
\text { membership }\end{array}$ & 0.136 & 0.343 & 0.203 & 0.402 & 0.369 & 0.483 & 0.381 & 0.486 \\
\hline $\begin{array}{l}\text { Unemployed or } \\
\text { out of labor force }\end{array}$ & 0.058 & 0.234 & 0.068 & 0.252 & 0.011 & 0.103 & 0.008 & 0.091 \\
\hline Employed & 0.936 & 0.245 & 0.924 & 0.264 & 0.801 & 0.399 & 0.811 & 0.391 \\
\hline Retired & 0.006 & 0.077 & 0.008 & 0.087 & 0.188 & 0.391 & 0.18 & 0.385 \\
\hline Beijing & 0.037 & 0.189 & 0.288 & 0.453 & 0.084 & 0.277 & 0.106 & 0.307 \\
\hline Shanxi & 0.087 & 0.282 & 0.119 & 0.324 & 0.128 & 0.335 & 0.154 & 0.361 \\
\hline Liaoning & 0.071 & 0.257 & 0.094 & 0.292 & 0.093 & 0.29 & 0.054 & 0.227 \\
\hline Jiangsu & 0.179 & 0.383 & 0.102 & 0.303 & 0.124 & 0.33 & 0.071 & 0.257 \\
\hline Anhui & 0.103 & 0.304 & 0.062 & 0.241 & 0.079 & 0.27 & 0.076 & 0.265 \\
\hline Henan & 0.229 & 0.42 & 0.087 & 0.282 & 0.106 & 0.308 & 0.086 & 0.281 \\
\hline Hubei & 0.077 & 0.267 & 0.057 & 0.232 & 0.13 & 0.337 & 0.08 & 0.271 \\
\hline Guangdong & 0.147 & 0.354 & 0.103 & 0.305 & 0.084 & 0.277 & 0.034 & 0.182 \\
\hline Yunnan & 0.029 & 0.168 & 0.025 & 0.155 & 0.108 & 0.31 & 0.216 & 0.411 \\
\hline Gansu & 0.04 & 0.197 & 0.063 & 0.243 & 0.064 & 0.244 & 0.124 & 0.33 \\
\hline Number of obs. & & 2208 & & & & 259 & & \\
\hline
\end{tabular}


Table A3. Descriptive Statistics for 2002

\begin{tabular}{|c|c|c|c|c|c|c|c|c|}
\hline \multirow[b]{3}{*}{ Variable } & \multicolumn{4}{|c|}{ Rural } & \multicolumn{4}{|c|}{ Urban } \\
\hline & \multicolumn{2}{|c|}{ Nonweighted } & \multicolumn{2}{|c|}{ Weighted } & \multicolumn{2}{|c|}{ Nonweighted } & \multicolumn{2}{|c|}{ Weighted } \\
\hline & Mean & Std. Dev. & Mean & Std. Dev. & Mean & Std. Dev. & Mean & Std. Dev. \\
\hline $\begin{array}{l}\text { Log } \\
\text { Consumption }\end{array}$ & 6.343 & 0.519 & 6.339 & 0.529 & 7.624 & 0.468 & 7.583 & 0.463 \\
\hline $\begin{array}{l}\text { Log augmented } \\
\text { Consumption }\end{array}$ & 6.604 & 0.53 & 6.635 & 0.549 & 7.971 & 0.473 & 7.921 & 0.47 \\
\hline $\begin{array}{l}\text { Log food } \\
\text { Consumption }\end{array}$ & 5.786 & 0.47 & 5.745 & 0.477 & 6.867 & 0.441 & 6.813 & 0.434 \\
\hline Log total income & 7.173 & 0.571 & 7.183 & 0.581 & 8.214 & 0.488 & 8.17 & 0.478 \\
\hline $\begin{array}{l}\text { Age of } \\
\text { household head }\end{array}$ & 45.957 & 10.2 & 46.573 & 10.304 & 48.271 & 11.476 & 48.058 & 11.531 \\
\hline Family size & 4.137 & 1.222 & 3.969 & 1.181 & 3.026 & 0.794 & 2.996 & 0.766 \\
\hline Share of children & 0.19 & 0.186 & 0.175 & 0.182 & 0.132 & 0.161 & 0.135 & 0.163 \\
\hline Male & 0.955 & 0.207 & 0.897 & 0.303 & 0.686 & 0.464 & 0.688 & 0.463 \\
\hline Education & 7.506 & 2.44 & 7.708 & 2.565 & 10.854 & 3.303 & 10.925 & 3.372 \\
\hline Ethnicity & 0.094 & 0.292 & 0.1 & 0.3 & 0.954 & 0.21 & 0.937 & 0.243 \\
\hline $\begin{array}{l}\text { Party } \\
\text { membership }\end{array}$ & 0.167 & 0.373 & 0.209 & 0.407 & 0.401 & 0.49 & 0.414 & 0.493 \\
\hline $\begin{array}{l}\text { Unemployed or } \\
\text { out of labor force }\end{array}$ & 0.095 & 0.293 & 0.122 & 0.327 & 0.034 & 0.183 & 0.034 & 0.181 \\
\hline Employed & 0.897 & 0.303 & 0.869 & 0.337 & 0.699 & 0.459 & 0.704 & 0.456 \\
\hline Retired & 0.008 & 0.087 & 0.009 & 0.094 & 0.266 & 0.442 & 0.262 & 0.44 \\
\hline Beijing & 0.039 & 0.194 & 0.268 & 0.443 & 0.072 & 0.259 & 0.089 & 0.285 \\
\hline Shanxi & 0.107 & 0.309 & 0.127 & 0.333 & 0.097 & 0.296 & 0.129 & 0.335 \\
\hline Liaoning & 0.109 & 0.312 & 0.137 & 0.344 & 0.118 & 0.322 & 0.075 & 0.263 \\
\hline Jiangsu & 0.114 & 0.318 & 0.067 & 0.25 & 0.125 & 0.331 & 0.061 & 0.239 \\
\hline Anhui & 0.114 & 0.318 & 0.064 & 0.244 & 0.09 & 0.286 & 0.087 & 0.282 \\
\hline Henan & 0.14 & 0.347 & 0.051 & 0.219 & 0.12 & 0.324 & 0.08 & 0.272 \\
\hline Hubei & 0.137 & 0.344 & 0.091 & 0.287 & 0.117 & 0.321 & 0.085 & 0.279 \\
\hline Guangdong & 0.123 & 0.328 & 0.069 & 0.253 & 0.079 & 0.27 & 0.035 & 0.183 \\
\hline Yunnan & 0.057 & 0.232 & 0.044 & 0.205 & 0.117 & 0.321 & 0.209 & 0.407 \\
\hline Gansu & 0.06 & 0.238 & 0.083 & 0.276 & 0.066 & 0.248 & 0.151 & 0.358 \\
\hline Number of obs. & & 3304 & & & & & 4468 & \\
\hline
\end{tabular}




\section{Figure A1. Timeline of Chinese Economic Reform}

End of Culture Revolution

The 3rd Plenary Session of the

11th Communist Party of China

Central Committee;

Started economic reform

Set up Special Economic Zones

in four cities: Shen Zhen, Zhu Hai, Shan Tou, and Xia Men.

Started to abandon the rigid

planning economy system

Started to reform the State-owned enterprises; allowed for more flexible labor policy

Student Demonstration in Beijing
1976

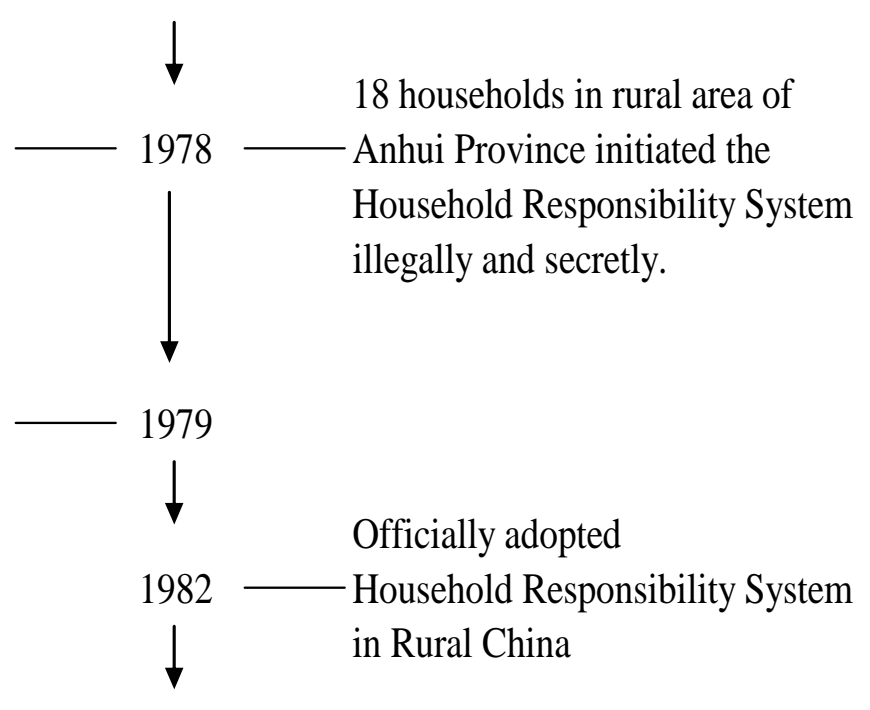

1984

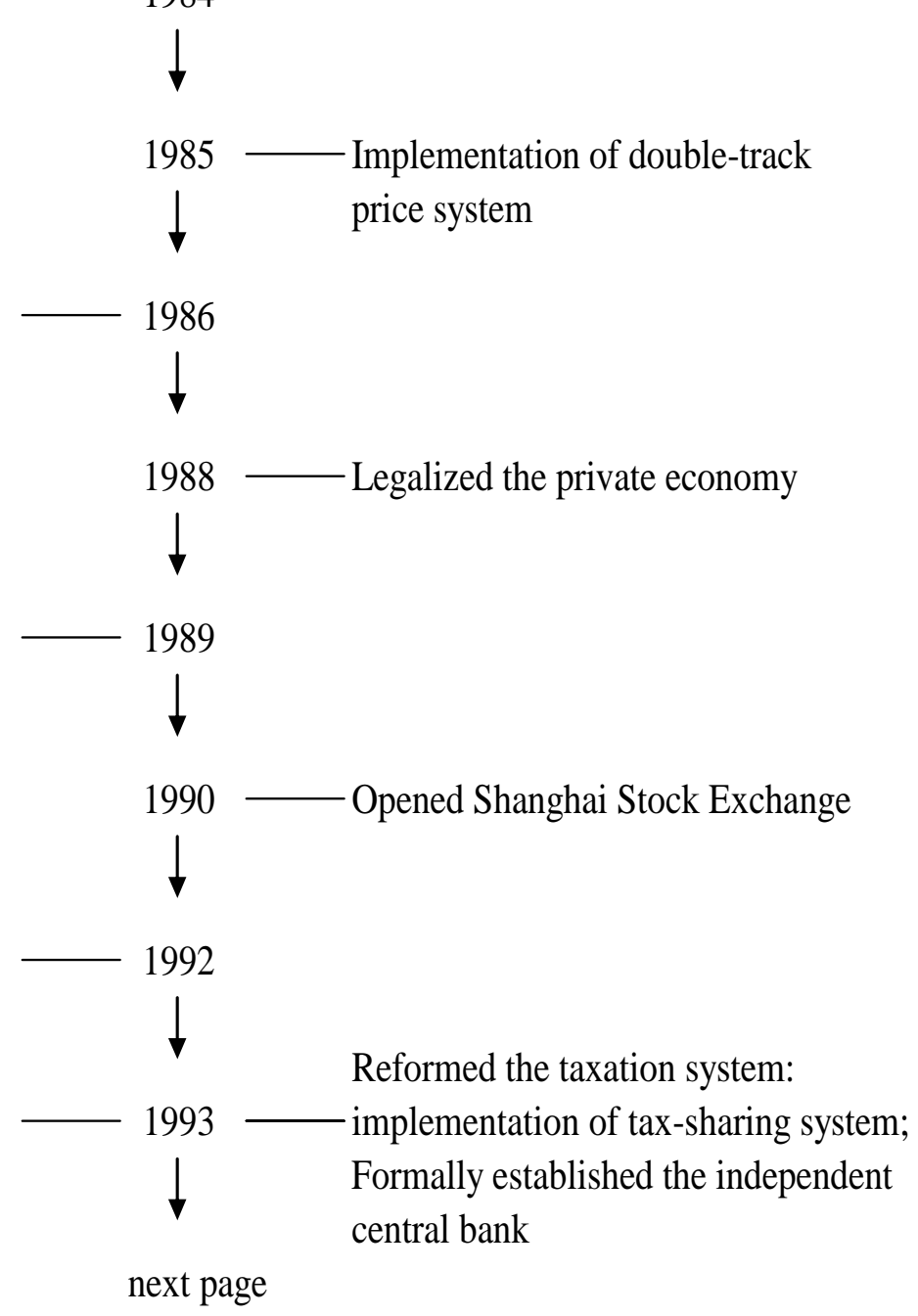




\section{Figure A1. Timeline of Chinese Economic Reform (Cont.)}

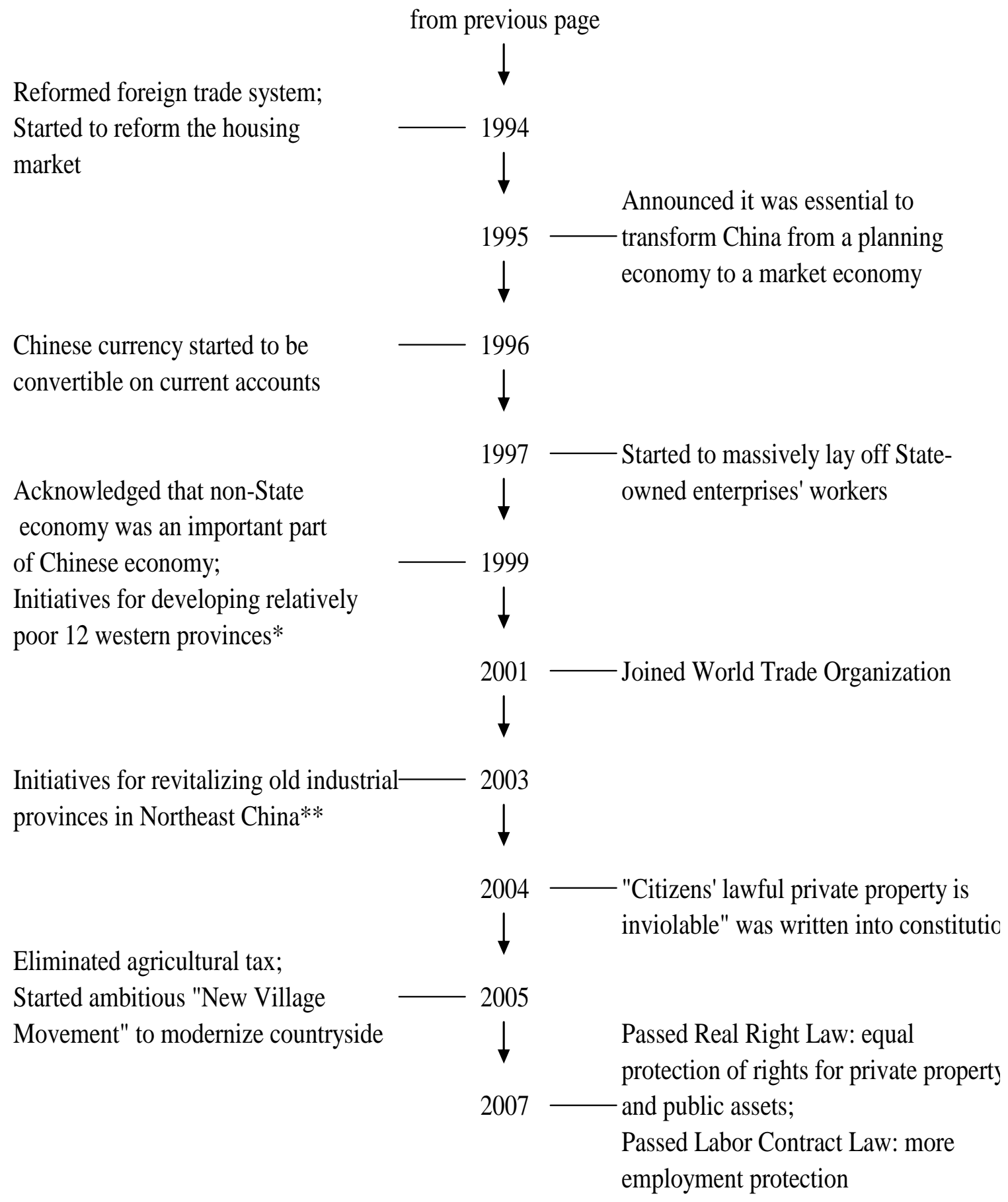

Note: * They are Chongqing, Gansu, Guangxi, Guizhou, Inner Mongolia, Ningxia, Qinghai, Shaanxi Sichuan, Tibet, Xinjiang, and Yunnan;

** They are Heilongjiang, Jilin, Liaoning and part of east Inner Mongolia.

Source: Author's illustration based on China Economic Weekly (2008) and Xinhua News Agency (2008). 
Figure A2. Provinces in the Sample

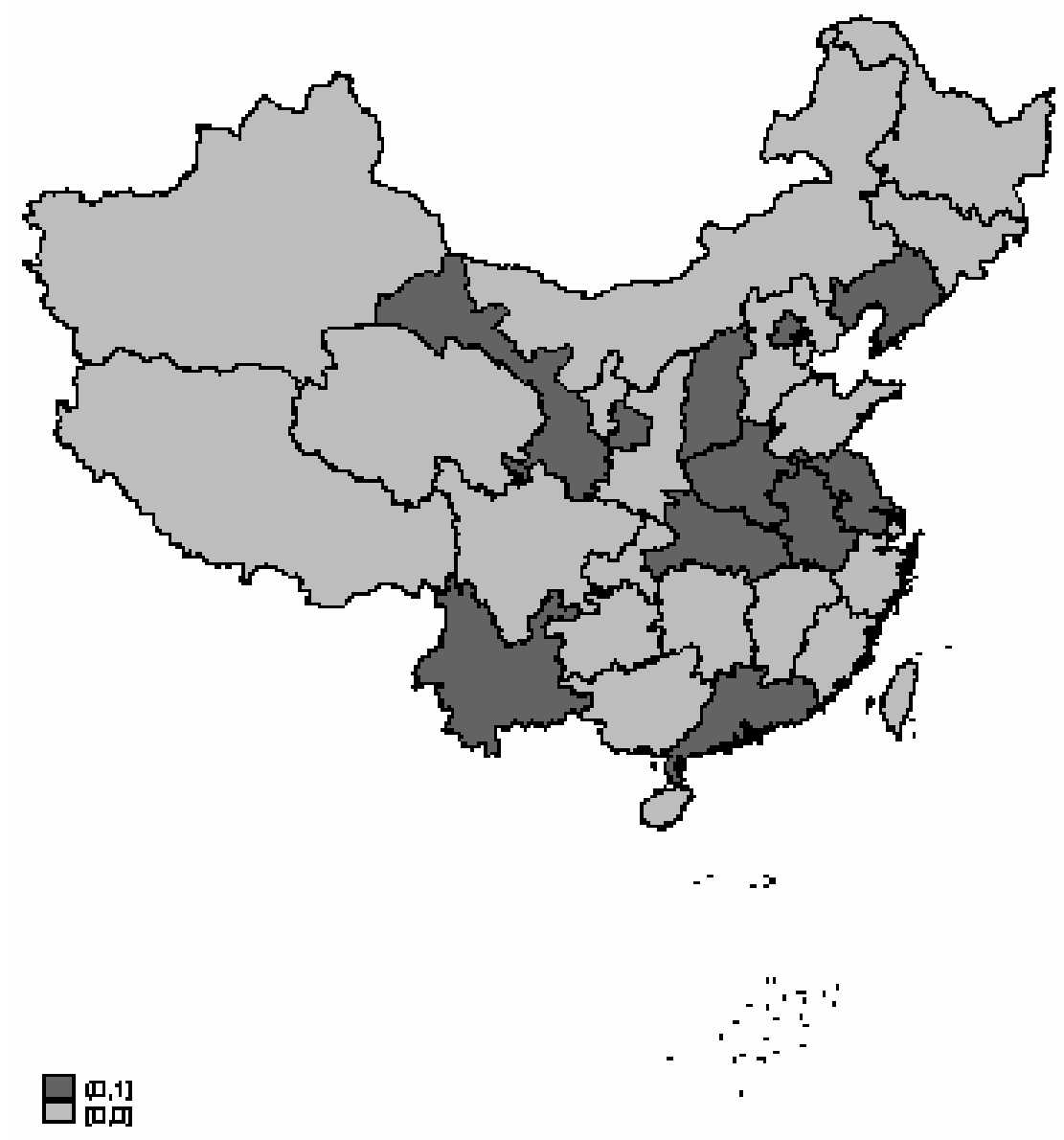

Note: 1. Darker areas are in our sample. They are Beijing, Shanxi, Liaoning, Jiangsu, Anhui, Henan, Hubei, Guangdong, Yunnan, and Gansu.

2. This map was produced by the Stata module SPMAP authored by Maurizio Pisati. The data used to generate this map is from ChinaW Dataset, ${ }^{\circledR}$ Zumou Yue, G. William Skinner, and Mark Henderson, Davis: University of California, Regional Systems Analysis Project, Jan. 2007, and PhysiographicMacroregions, ${ }^{\circ}$ G. William Skinner, Mark Henderson, and Zumou Yue, Davis: University of California, Regional Systems Analysis Project, Jan. 2007. 
Figure A3. Education in Urban and Rural China

Panel A. Distribution of Education Categories in Urban and Rural China

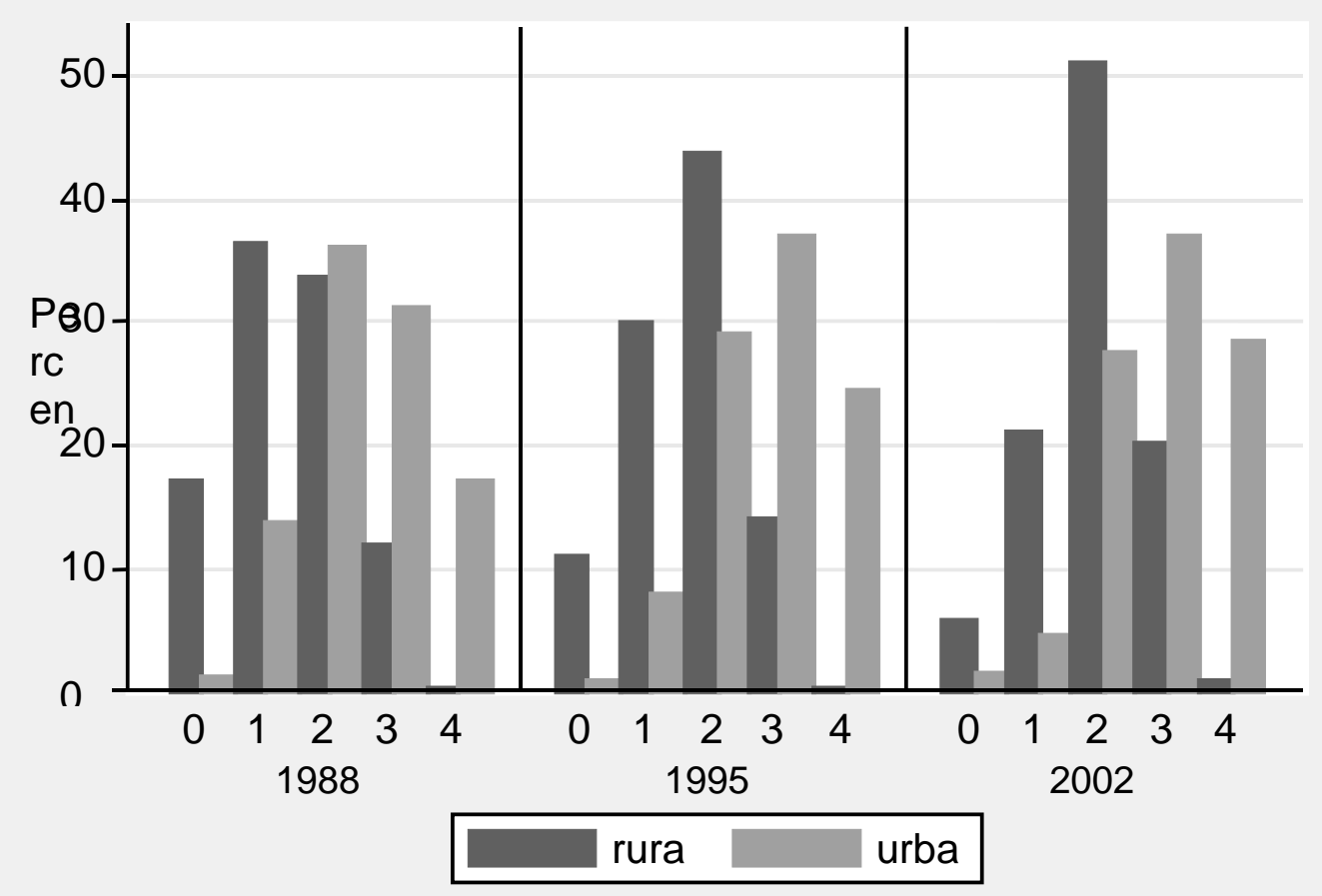

Notes:0-below primary school;1-primary school;2-middle school;3-high school;4-college and

Panel B. Urban-Rural Difference in Coefficient of Education

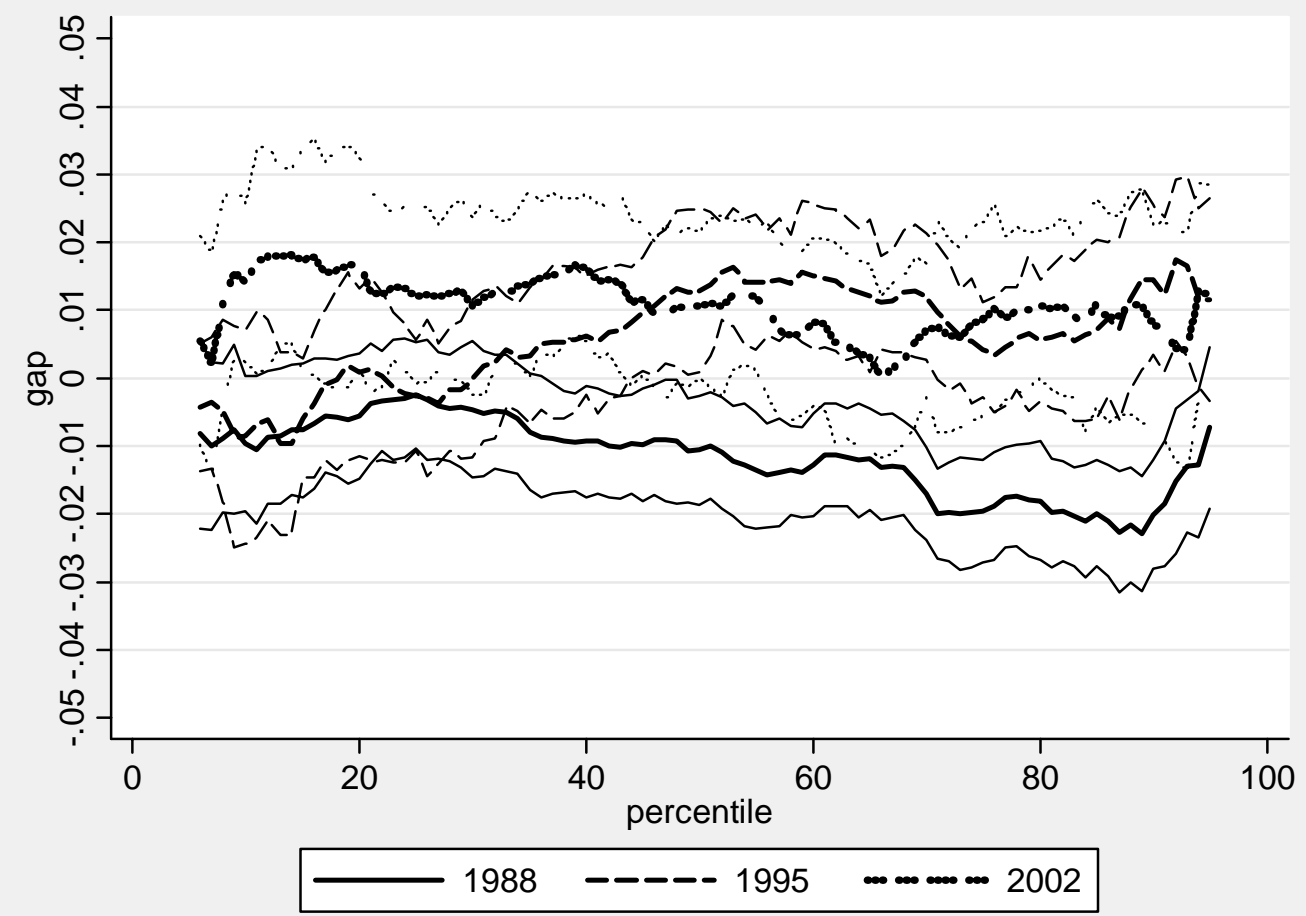

Note: Corresponding light lines are bounds for 95\% confidence intervals. 
Figure A4. Quantile Decompositions for Income

Panel A. Urban-Rural Decompositions by Year

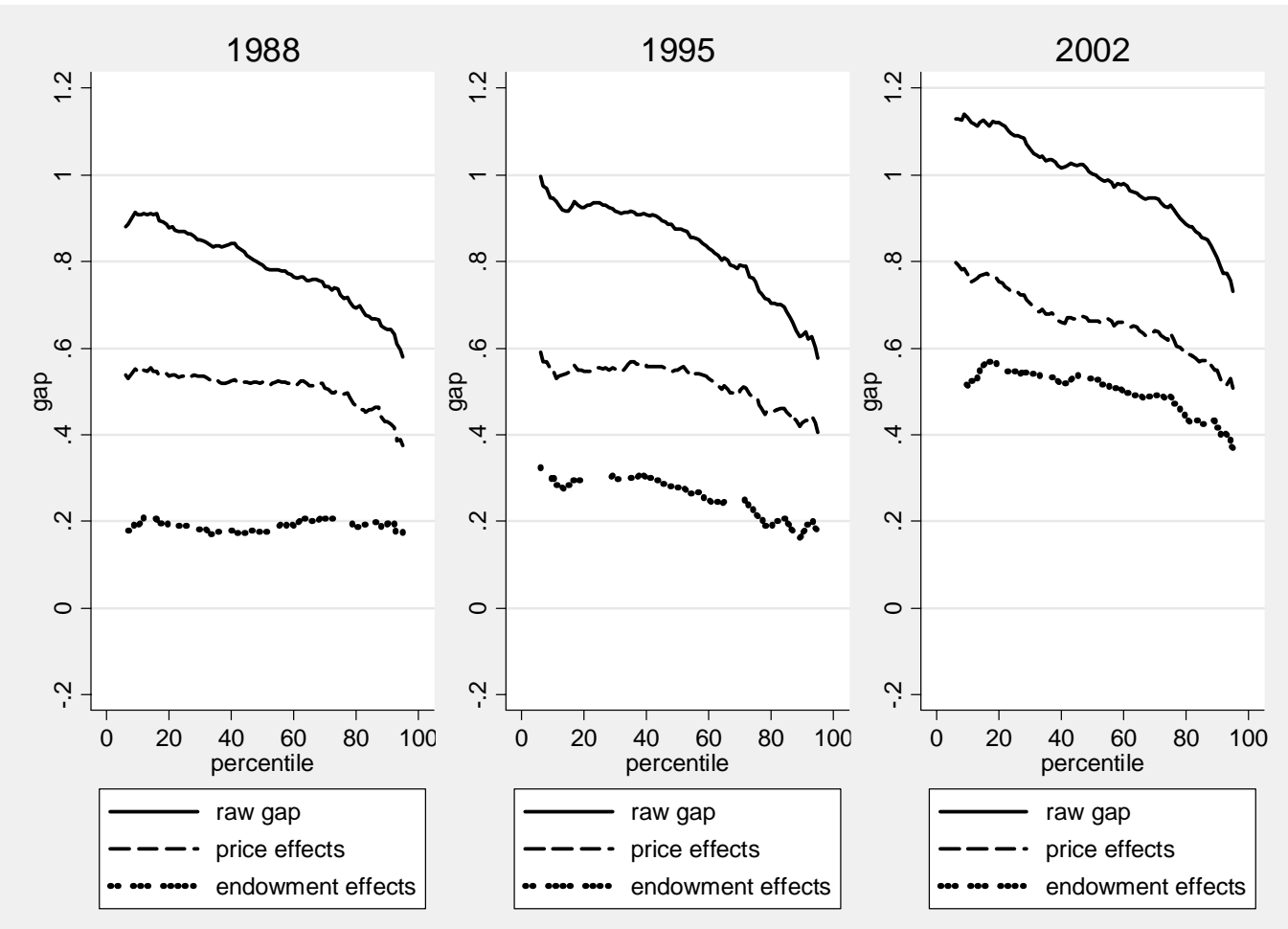

Panel B. Decompositions over Time by Urban and Rural Areas

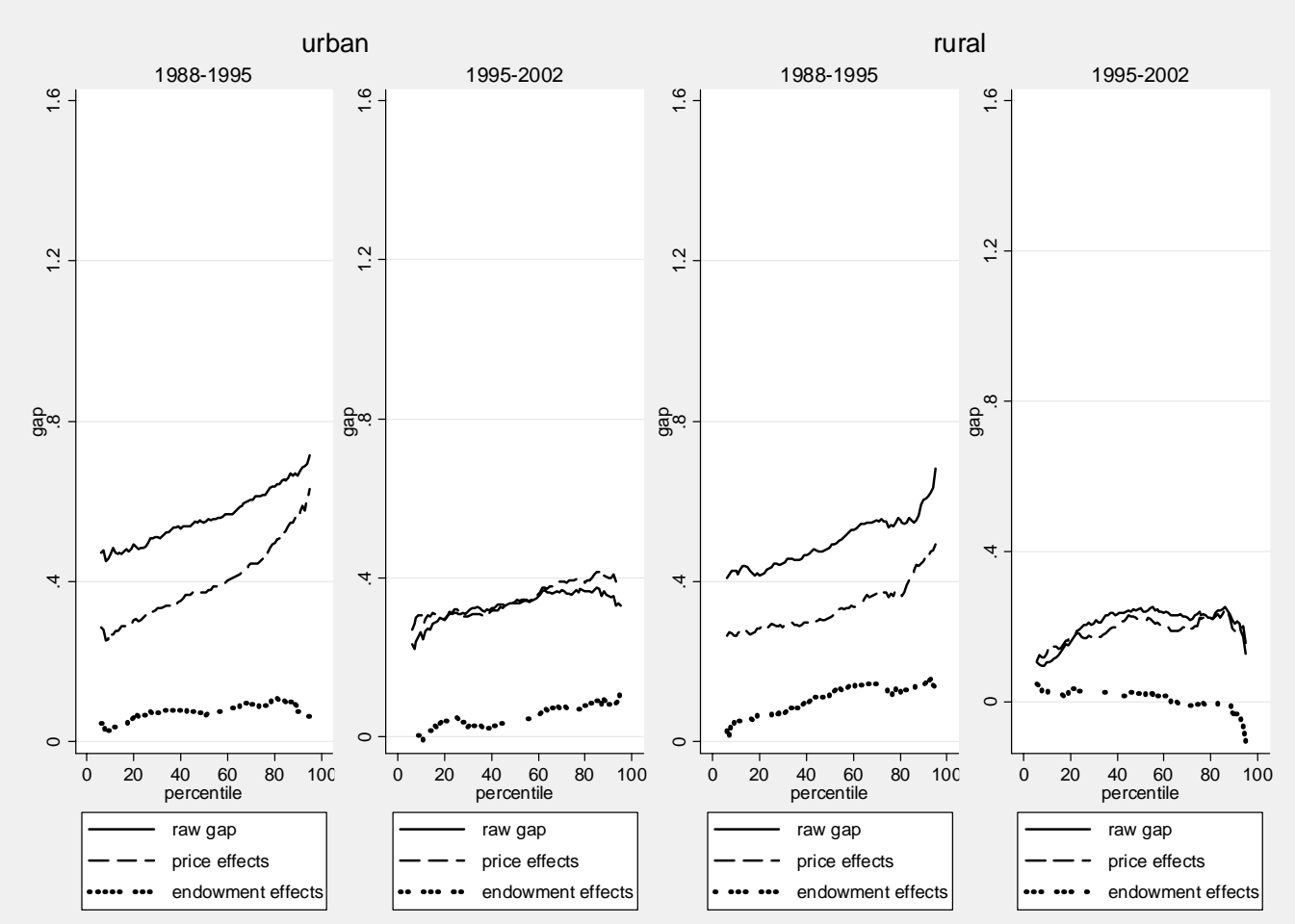


Figure A5. Quantile Decompositions with Old OECD Equivalence Scale Adjustment

Panel A. Urban-Rural Decompositions by Year

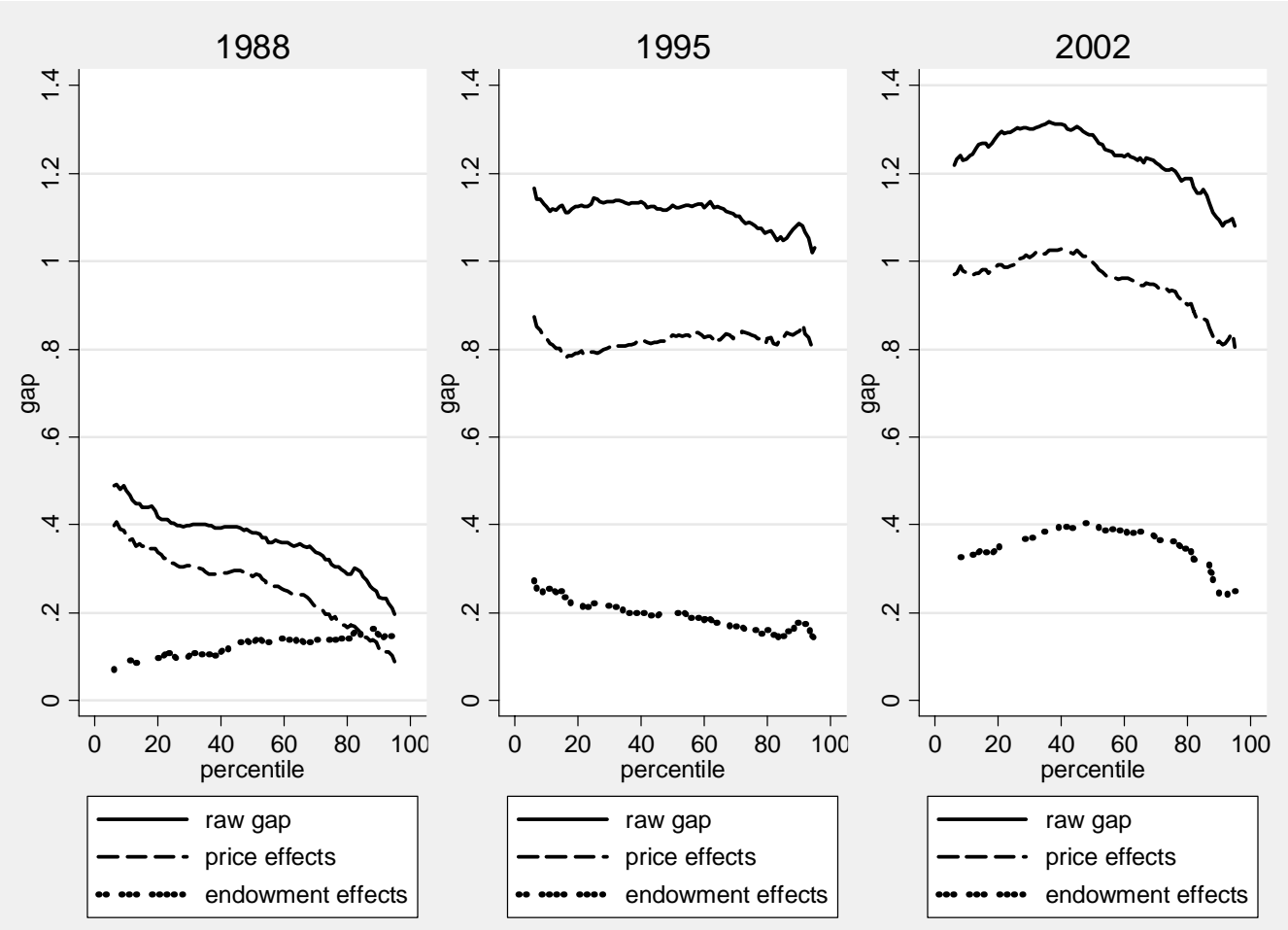

Panel B. Decompositions over Time by Urban and Rural Areas

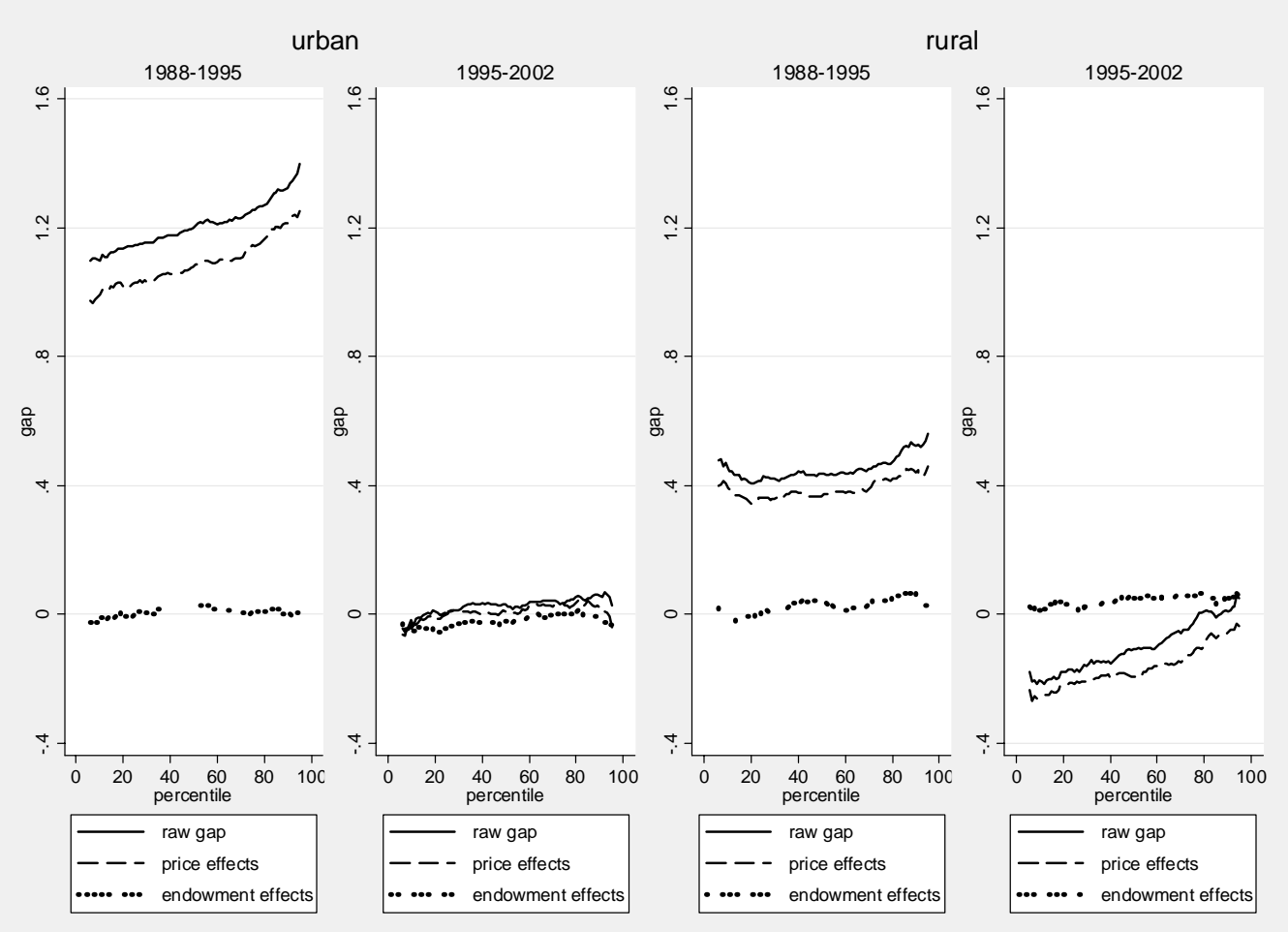


Figure A6. Quantile Decompositions without Beijing

Panel A. Urban-Rural Decompositions by Year

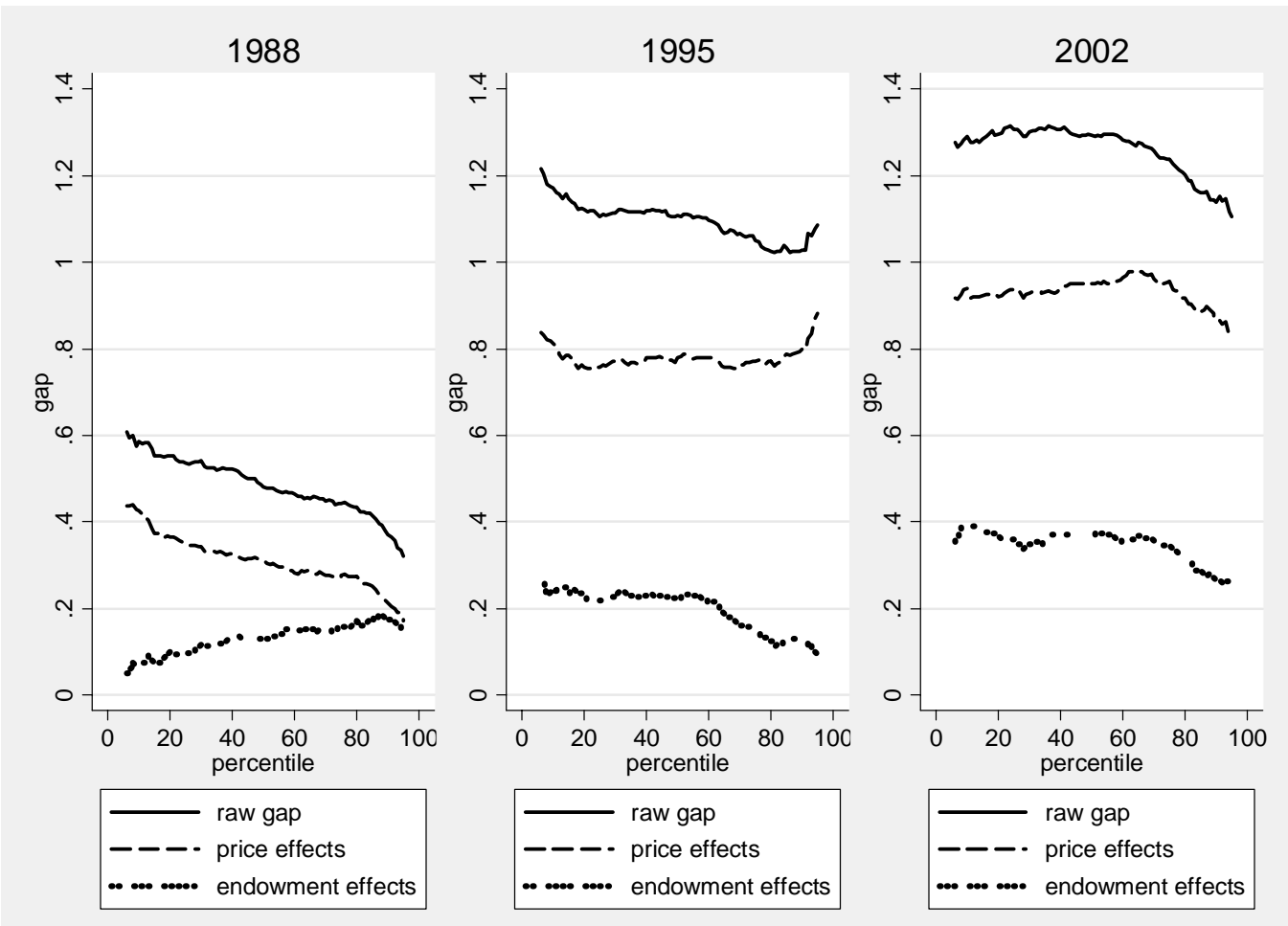

Panel B. Decompositions over Time by Urban and Rural Areas

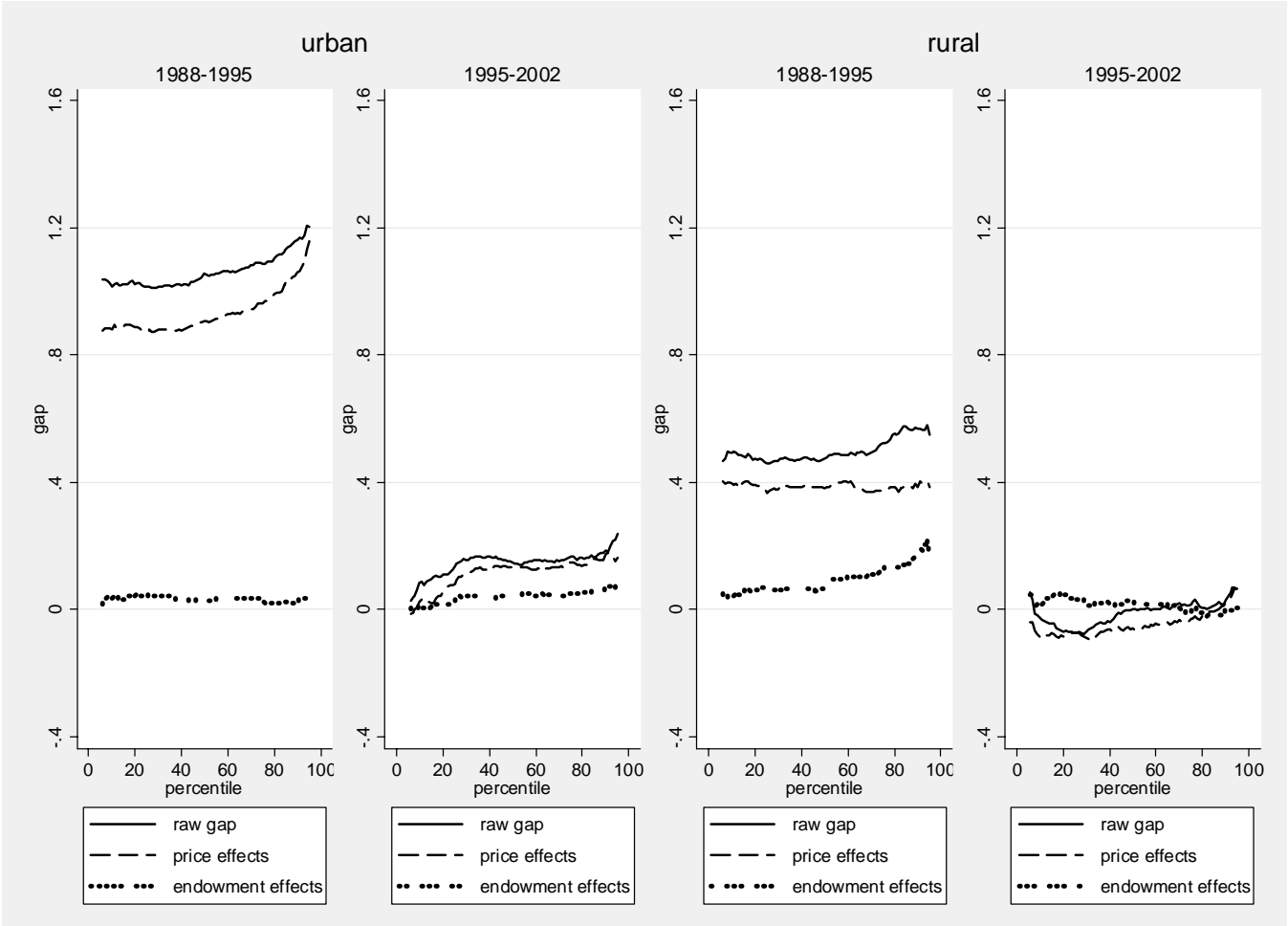



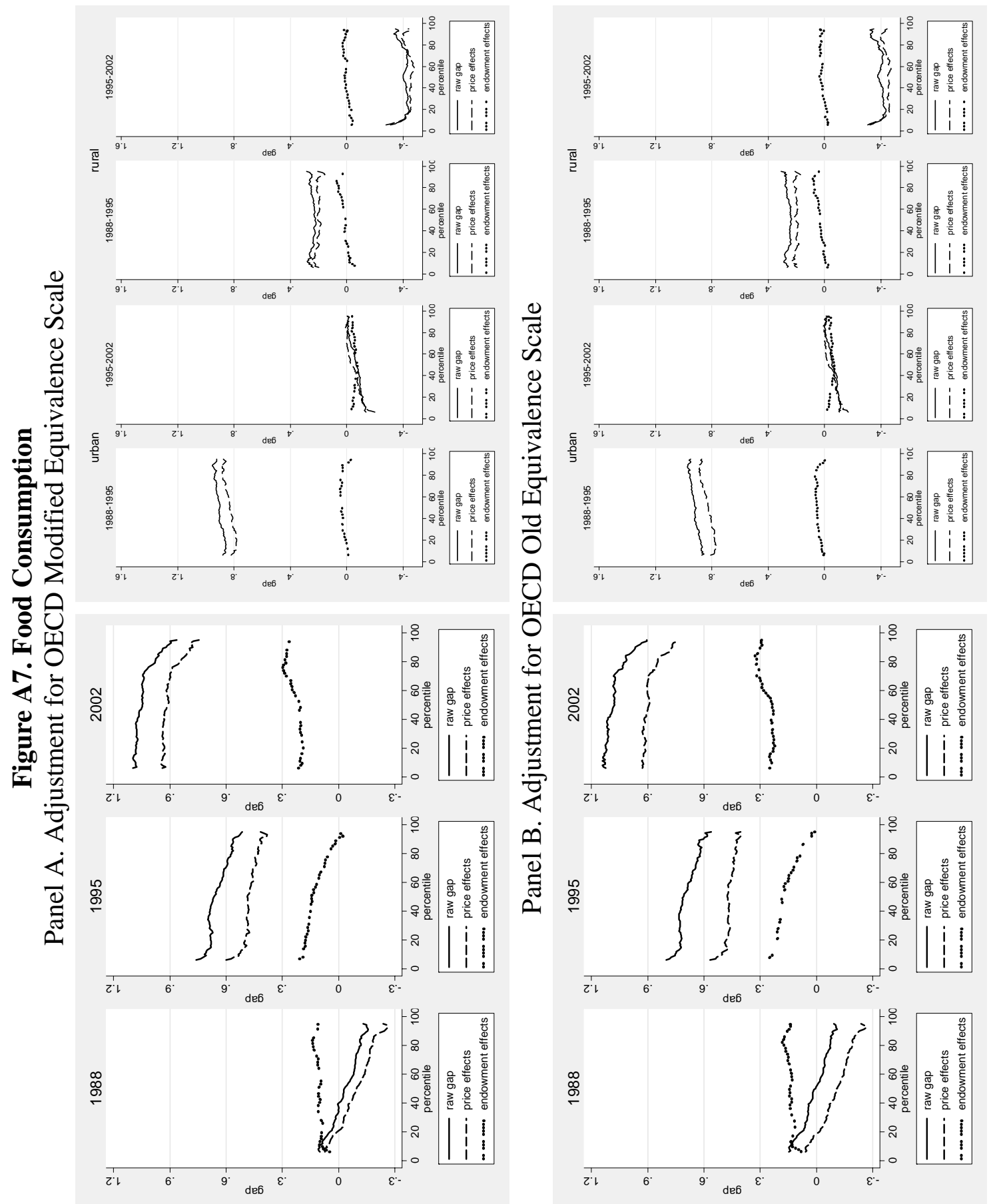

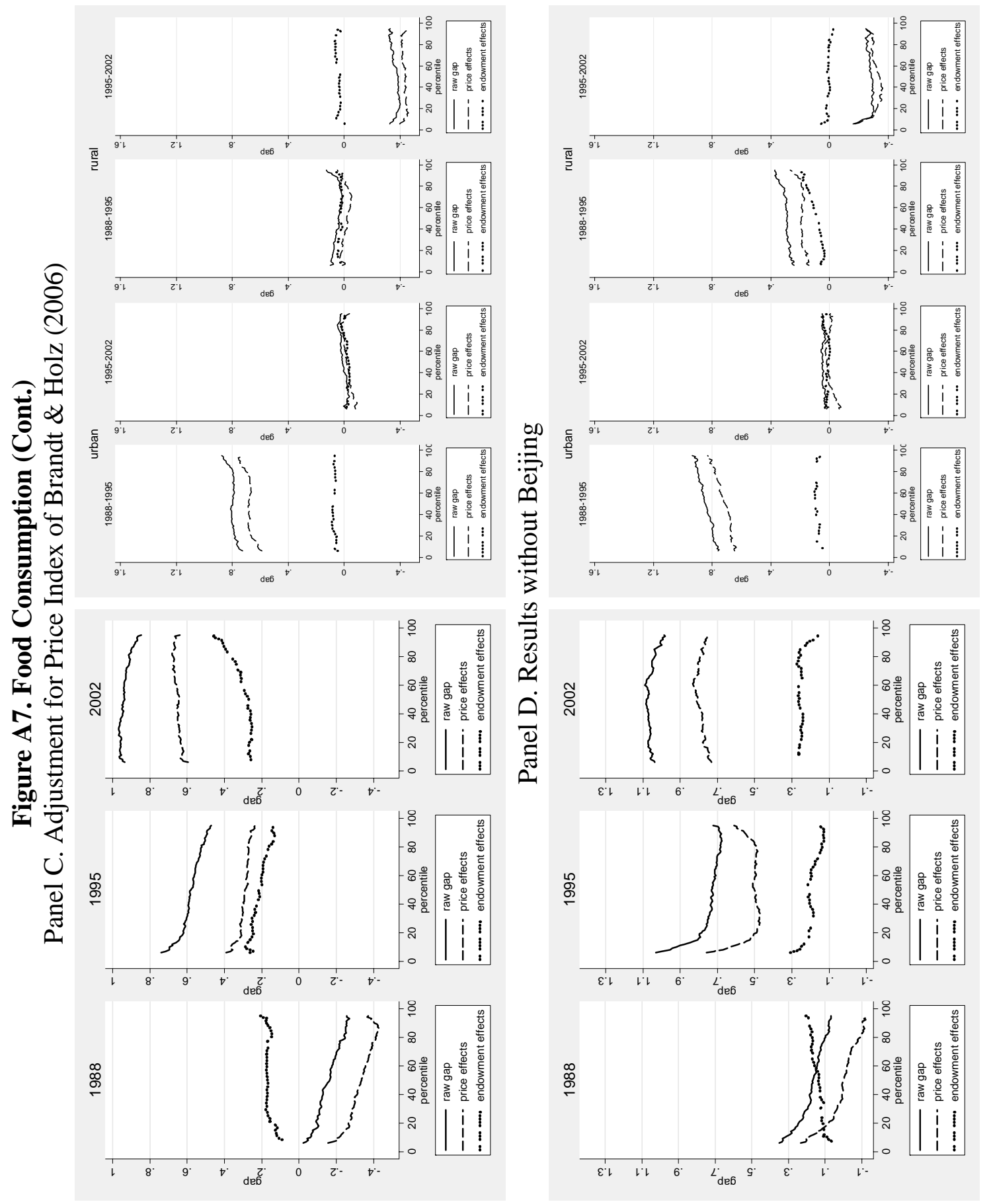